\title{
Neurochemical Signaling of Reward and Aversion to Ventral Tegmental Area Glutamate Neurons
}

\author{
Dillon J. McGovern, ${ }^{1}$ Abigail M. Polter, ${ }^{2}$ and David H. Root $^{1}$ \\ ${ }^{1}$ Department of Psychology and Neuroscience, University of Colorado, Boulder, Colorado 80301, and ${ }^{2}$ Department of Pharmacology and Physiology, \\ George Washington University, Washington, DC 20052
}

Ventral tegmental area (VTA) glutamate neurons signal and participate in reward and aversion-based behaviors. However, the neurochemical mechanisms that underlie how these neurons contribute to motivated behaviors is unknown. We used a combination of optical sensors to identify how distinct neurochemical inputs to VTA glutamate neurons participate in motivated behavior within female and male transgenic mice. Activity of glutamate inputs to VTA glutamate neurons increased for both reward-predicting and aversion-predicting cues and aversive outcomes, but subpopulations of glutamate inputs were increased or decreased by reward. For both reward and aversion-based cues and outcomes, activity of GABA inputs to VTA glutamate neurons mostly decreased. GCaMP recordings showed overall population increases in VTA glutamate neuron intracellular calcium during reward and aversion-based cues and outcomes. Electrophysiological recordings of VTA VGluT2 neurons showed that glutamate receptor activation increases firing while loss of excitation via glutamate receptor blockade decreases firing. GABA-A receptor activation decreased VTA glutamate neuron firing but GABA-A receptor blockade did not significantly change VTA glutamate neuron firing. Electrophysiological recordings in coordination with our sensor data suggest that glutamate inputs strongly regulate VTA glutamate neuron participation in diverse motivated behaviors.

Key words: aversion; GABA; GCaMP; glutamate; reward; VTA

\section{Significance Statement}

Glutamate and GABA are the primary excitatory and inhibitory neurotransmitters of the nervous system. However, identifying how these neurotransmitters regulate motivated behavior has remained challenging because of a lack of tools (1) capable of measuring neurotransmission at the temporal scale of motivated behaviors and (2) capable of capturing chemical signaling onto genetically-distinct neuronal populations. We have overcome these obstacles by implementing genetically-encoded fluorescent indicators to monitor both glutamate and GABA input dynamics exclusively to ventral tegmental area (VTA) glutamate neurons during reward and aversion-based behaviors. We identify that glutamate and GABA inputs to VTA glutamate neurons differentially and dynamically signal reward and aversion-based cues and outcomes. This research provides foundational evidence that links distinct neurotransmitters to motivated behaviors regulated by VTA glutamate neurons.

Received June 4, 2020; revised Apr. 29, 2021; accepted May 5, 2021.

Author contributions: D.J.M., A.M.P., and D.H.R. designed research; D.J.M., A.M.P., and D.H.R. performed research; D.J.M., A.M.P., and D.H.R. analyzed data; D.J.M., A.M.P., and D.H.R. wrote the paper.

This work was supported by the National Institutes of Health National Institute on Drug Abuse Award R01DA047443 (to D.H.R.). This work was also supported by the Webb-Waring Biomedical Research Award from the Boettcher Foundation, the CO-PILOT award from the Colorado Clinical and Translational Sciences Institute, a 2020 National Alliance for Research on Schizophrenia and Depression Young Investigator grant from the Brain and Behavior Research Foundation, an anonymous benefactor, and The University of Colorado (D.H.R.). Further support was provided by NIH Grants R00MH106757 and R01MH122712, a grant from the Margaret Q. Landenberger Foundation, and a 2019 NARSAD Young Investigator grant (to A.M.P.). We thank Dr. Loren Looger and Dr. Jonny Marvin for generously providing viruses encoding (re-dependent iGluSnFR and iGABASnFR, Dr. Karl Deisseroth for generously providing the Credependent enhanced yellow fluorescent protein (eYFP) virus, Addgene for providing the Cre-dependent GCaMP vector, and Alysabeth Phillips for photometry piloting.

The authors declare no competing financial interests.

Correspondence should be addressed to David H. Root at david.root@colorado.edu. https://doi.org/10.1523/JNEUROSCI.1419-20.2021

Copyright $\odot 2021$ the authors

SfN exclusive license.

\section{Introduction}

The ventral tegmental area (VTA) is a cellularly heterogeneous midbrain structure (Barrot, 2014; Scaplen and Kaun, 2016; Morales and Margolis, 2017) that plays important roles in reinforcement, reward (Wise and Bozarth, 1981), aversion (Cohen et al., 2012; Holly and Miczek, 2016; Levi et al., 2020), and drugseeking behavior (Pascoli et al., 2015). Dopamine neurons in the lateral VTA contribute to reinforcing behavioral action via mesocorticolimbic targets (Wise, 2004). Additionally, local VTA GABAergic neurons may disinhibit VTA dopamine neurons to support reward (Bocklisch et al., 2013; Jennings et al., 2013; Corre et al., 2018) or may disrupt reward processing and promote aversion following their activation (Tan et al., 2012; van Zessen et al., 2012). More recently, a distinct subpopulation of VTA neurons that expresses the vesicular glutamate transporter (VGluT2) has been identified in the medial VTA of mice, rats, non-human primates, and humans (Yamaguchi et al., 2007; Root 
et al., 2016). These neurons release glutamate both locally within the VTA and distally to reward and aversion-related brain structures, such as lateral habenula and nucleus accumbens (Morales and Margolis, 2017). Initial exploration has revealed that VTA VGluT2 neurons heterogeneously participate in reward and aversion-based behaviors.

Photo-tagged VTA VGluT2 neuronal recordings show that nearly all of these cells increase their firing to aversive facial air puffs (Root et al., 2018). However, firing within these neurons is heterogenous for rewarding stimuli. Subsets of VTA VGluT2 neurons are reliably distinguished by whether they increase or decrease firing following reward receipt (Root et al., 2018). This heterogeneity in firing likely contributes to the functional diversity of these neurons in motivated behavior. Optogenetic stimulation of VTA VGluT2 neurons can result in either place preference or place aversion (Root et al., 2014a; Wang et al., 2015; Yoo et al., 2016; Bimpisidis et al., 2019). Stimulation parameters and projection targets both influence when mice exhibit reward or aversion-based behavior following VTA VGluT2 neuron stimulation, which indicates that the role of these neurons in motivation is complex. Our work in the following experiments aimed to determine the neurochemical mechanisms that underlie how VTA VGluT2 neurons signal reward and aversion. To accomplish this, we recorded from mice expressing geneticallyencoded neurotransmitter sensing fluorescent reporters (SnFRs) to capture glutamate and GABA input to VTA VGluT2 neurons. We found that glutamate inputs to VTA VGluT2 neurons were divided into two populations, one population that increases for reward and another that decreases. In contrast, glutamate inputs homogeneously increased in response to aversive stimuli. GABA inputs to VTA VGluT2 neurons mostly decreased following both rewarding and aversive stimuli. While GABA inputs were altered by motivation-related stimuli and behaviors, our electrophysiological recordings indicated that glutamate receptor activity drives both increasing and decreasing basal firing of VTA VGluT2 neurons. Together, these results (1) provide new neurochemical insights into how VTA VGluT2 neurons integrate multiple neurotransmitters during reward and aversion, (2) suggest that glutamate strongly regulates VTA VGluT2 neuron activity, and (3) we hypothesize that glutamatergic inputs contribute to the diversity in signaling of reward and aversion by VTA VGluT2 neurons.

\section{Materials and Methods}

All animal procedures were performed in accordance with National Institutes of Health Guidelines, and approved by the University of Colorado Institutional Animal Care and Use Committee or the George Washington University Institutional Animal Care and Use Committee.

\section{Intracranial injections and fiber optic implants}

Male and female VGluT2-IRES::Cre mice (Slc17a6 ${ }^{\mathrm{tm} 2 \text { (cre)Lowl/J; The }}$ Jackson Laboratory; $18-35$ g, 12-22 weeks) were used $(n=42)$. Mice were anesthetized with 1-3\% isoflurane. AAV2/1-hSyn-FLEX-SFiGluSnFR-A184S $\left(n=11,8\right.$ male, three female, titer $\left.2 \times 10^{12}\right)$, AAV2/1hSyn-FLEX-iGABASnFR-F102G $(n=13,11$ male, 2 female, titer 2 $\left.\times 10^{12}\right)$, AAV1-hSyn-FLEX-GCAMP6m $(n=10$, three male, 10 female, titer $\left.2 \times 10^{12}\right)$, or AAV8-EF1 $\alpha$-DIO-eYFP $(n=11,7$ male, four female, titer $\left.3 \times 10^{12}\right)$ was injected in VTA $(500 \mathrm{nl} ; 100 \mathrm{nl} / \mathrm{min} ;-3.2 \mathrm{~mm}$ anteroposterior, $0.0 \mathrm{~mm}$ mediolateral, $-4.4 \mathrm{~mm}$ dorsoventral) using an UltraMicroPump, Nanofil syringes, and 35-gauge needles (WPI). Syringes were left in place for $10 \mathrm{~min}$ following injections to minimize diffusion. For neurotransmitter and calcium imaging experiments, an optic fiber $(400-\mu \mathrm{m}$ core diameter, 0.66 NA, Doric Lenses) was implanted dorsal to VTA ( -3.2 anteroposterior, -1.0 mediolateral at $9.5^{\circ},-4.2$ dorsoventral) and secured with skull screws and dental cement. No statistically significant differences between male and female mice were observed; all data were therefore pooled.

\section{Experimental design and statistical analysis}

Reward task behavioral training

After at least three weeks following injection of viral constructs encoding iGluSnFR, iGABASnFR, or GCaMP, mice were food restricted to $85 \%$ free-feeding body weight. Mice were brought to chambers equipped with a three-dimensionally printed reward receptacle coupled to a syringe pump, two nose poke devices with cue lights, and a speaker (MedAssociates). Mice were initially trained in the reward task. During the reward task, either a conditioned stimulus $(6-\mathrm{kHz}$ tone and cue light activation for $10 \mathrm{~s}$; RewCS + ) was presented that co-terminated with the delivery of $8 \%$ sucrose to the reward receptacle $(20 \mu \mathrm{l}$; pump onset $8.5 \mathrm{~s}$ to offset at $10 \mathrm{~s}$ after RewCS + onset) or a neutral conditioned stimulus (white noise for $10 \mathrm{~s}, 72 \mathrm{~dB}$; RewCS-) was presented that resulted in no sucrose delivery. RewCS + and RewCS- trials were randomly presented, separated by a variable interval 90-s schedule (range 60-120 s). Each training session ended after 30 RewCS + and 30 RewCS- trials. The percentage of trials in which mice entered the reward port during RewCS+ or RewCS- trials was collected daily. Head entries were detected by infrared beam breaks within the reward magazine (MED-Associates). Once mice reached at least three consecutive days of $70 \%$ or greater RewCS + trials entering the reward port, neuronal recording commenced. Mice trained for approximately four weeks before being recorded (mean \pm SEM: $27.75 \pm 0.889 \mathrm{~d}$ ). During the neuronal recording, 40 RewCS + and 40 RewCS- trials were presented. In addition, $90 \%$ of RewCS + trials resulted in reward delivery and 10\% of RewCS + trials resulted in reward omission (termed reward CS+ error trials, RewCSe). One iGABASnFR mouse did not meet reward recording criterion and was only neuronally examined in the aversion task.

\section{Aversion task behavioral training}

After recording neuronal activity in the reward task, mice were fed ad libitum. Mice were returned to the conditioning chamber over $4 \mathrm{~d}$. The chamber context was altered by removing the reward receptacle, and cue lights remained illuminated for the entire duration of the task. During the aversion task, either a conditioned stimulus $(10-\mathrm{kHz}$ tone, $10 \mathrm{~s}$; ShkCS+) was presented that co-terminated with the delivery of foot shock $(0.5 \mathrm{~s}, 0.5 \mathrm{~mA}$, onset $9.5 \mathrm{~s}$ after ShkCS + onset) or a neutral conditioned stimulus (white noise for $10 \mathrm{~s}, 72 \mathrm{~dB}$; ShkCS-) was presented that resulted in no foot shock. ShkCS + and ShkCS- trials were randomly presented, separated by a 60 - to 120 -s variable intertrial interval. Each training session ended after 10 ShkCS + and 10 ShkCS- trials. After $3 \mathrm{~d}$ of training, neuronal recording commenced. A separate group of wildtype C57BL/6J mice ( $n=7$ male) received the same training on the aversion task as described. However, before foot shock conditioning, the ShkCS+ and ShkCS- cues were randomly presented in the manner described above except that foot shock was not delivered. Four days of foot shock conditioning with the ShkCS + and ShkCS- then commenced as described above. Video recordings $(10 \mathrm{~Hz}$, Synapse, TDT) were collected on the first session without foot shock delivery and during the last session with foot shock delivery. Total seconds of freezing, defined as the absence of movement except for breathing and postural adjustments, was scored from videos during the ShkCS + and ShkCS- cues.

\section{Cued licking task training}

Three weeks following injection of Cre-dependent GCaMP, a subset of mice ( $n=3$ female) was food restricted to $85 \%$ free-feeding body weight. Mice were brought to chambers equipped with a metal spout coupled to a syringe pump, two nose poke devices with cue lights, and a speaker (Med-Associates). During initial training ( $4 \mathrm{~d}, 60 \mathrm{~min}$ each), a conditioned stimulus $(6-\mathrm{kHz}$ tone and cue light activation for $20 \mathrm{~s}$; $\mathrm{CS}+)$ was presented and at the onset of the cue, $20 \mu \mathrm{l}$ of $8 \%$ sucrose was delivered through the spout. The CS + was presented on average every $75 \mathrm{~s}$. Licks were detected by lickometer (Med-Associates). Each five additional licks on the spout during the CS+ earned additional $40 \mu \mathrm{l}$ of reward. After initial training, the CS+ was presented as described in initial training, 
with the exception that sucrose was not delivered at the onset of the $\mathrm{CS}+$ and that each additional two licks on the spout during the CS+ earned $40 \mu \mathrm{l}$ of reward. This training regimen of lick-dependent reward continued for at least one week before recording. During the photometry recording, $80 \%$ of cued trials were CS+ trials that resulted in reward. Twenty percent of trials during the photometry recording were CS error trials (CSe) where the CS + was presented but no sucrose was delivered following licking.

\section{Neurotransmitter and calcium fiber photometry recordings}

iGluSnFR, iGABASnFR, or GCaMP6m was excited at two wavelengths, 465- and 405-nm isosbestic control, by amplitude modulated signals from two light-emitting diodes reflected off dichroic mirrors and then coupled into an optic fiber as previously described (Barker et al., 2017). Sensor signals emitted and their isosbestic control emissions were returned through the same optic fiber and acquired using a femtowatt photoreceiver (Newport), digitized at $1 \mathrm{kHz}$, and then recorded by a real-time signal processor (Tucker Davis Technologies). Behavioral timestamps of RewCS + onset, RewCS- onset, RewCSe onset, reward port entries, spout licks, reward delivery, ShkCS+ onset, ShkCS- onset, and foot shock delivery were digitized in Synapse software (Tucker Davis Technologies) by TTL input from Med-PC (Med-Associates).

\section{Neurotransmitter and calcium signal analyses}

Analysis of the recorded neurotransmitter and calcium signals was performed using custom-written MATLAB scripts. Signals (465 and $405 \mathrm{~nm})$ were down sampled $(10 \times)$ and perievent time histograms were created trial-by-trial between $-20 \mathrm{~s}$ and $+30 \mathrm{~s}$ surrounding each event analyzed. For each trial, data were detrended by regressing the isosbestic control signal $(405 \mathrm{~nm})$ on the sensor signal $(465 \mathrm{~nm})$ and then generated a predicted $405-\mathrm{nm}$ signal using the linear model generated during the regression. The predicted $405-\mathrm{nm}$ channel was subtracted from the 465-nm signal to remove movement, photo-bleaching, and fiber bending artifacts (dF; Barker et al., 2017). Normalized dF was calculated by zscoring each trial, where the mean and standard deviation of the $z$ score was calculated between -3 and $0 \mathrm{~s}$.

\section{Slice preparation}

Male and female VGluT2-IRES::Cre mice ( $n=18,9$ male and 9 female) were injected with Cre-dependent AAV8-EF1 $\alpha$-DIO-eYFP at The University of Colorado. After at least three weeks, mice were shipped to George Washington University for slice physiology recording. After one week of acclimation, acute coronal slices were prepared as previously described (Polter et al., 2018) from deeply anesthetized mice. Mice were perfused with $34^{\circ} \mathrm{C}$ NMDG ringer: $92 \mathrm{~mm}$ NMDG, $2.5 \mathrm{~mm} \mathrm{KCl}, 1.2 \mathrm{~mm}$ $\mathrm{NaH}_{2} \mathrm{PO}_{4}, 30 \mathrm{~mm} \mathrm{NaHCO}, 20$ mм HEPES, $25 \mathrm{~mm}$ glucose, $5 \mathrm{~mm}$ sodium ascorbate, $2 \mathrm{~mm}$ thiourea, $3 \mathrm{~mm}$ sodium pyruvate, $10 \mathrm{~mm} \mathrm{MgSO}_{4}$, and $0.5 \mathrm{~mm} \mathrm{CaCl}_{2}$ (Ting et al., 2014). Following perfusion, the brain was rapidly dissected and coronal slices $(220 \mu \mathrm{M})$ were prepared in warmed NMDG ringer using a vibratome. Slices recovered for $1 \mathrm{~h}$ at $34^{\circ} \mathrm{C}$ in oxygenated HEPES holding solution: $86 \mathrm{~mm} \mathrm{NaCl}, 2.5 \mathrm{~mm} \mathrm{KCl}, 1.2 \mathrm{~mm}$ $\mathrm{NaH}_{2} \mathrm{PO}_{4}, 35 \mathrm{~mm} \mathrm{NaHCO}, 20$ mм HEPES, $25 \mathrm{~mm}$ glucose, $5 \mathrm{~mm}$ sodium ascorbate, $2 \mathrm{~mm}$ thiourea, $3 \mathrm{~mm}$ sodium pyruvate, $1 \mathrm{~mm} \mathrm{MgSO}$, and $2 \mathrm{~mm} \mathrm{CaCl}_{2}$ (Ting et al., 2014) and then were held in the same solution at room temperature until use.

\section{Electrophysiology}

Electrophysiological recordings were performed using a Sutterpatch integrated patch amplifier. Midbrain slices were continuously perfused at $1.5-2 \mathrm{ml} / \mathrm{min}$ with $\mathrm{ACSF}\left(28-32^{\circ} \mathrm{C}\right)$ containing the following: $126 \mathrm{~mm}$ $\mathrm{NaCl}, 21.4 \mathrm{~mm} \mathrm{NaHCO}$, $2.5 \mathrm{~mm} \mathrm{KCl}, 1.2 \mathrm{~mm} \mathrm{NaH}_{2} \mathrm{PO}_{4}, 2.4 \mathrm{~mm} \mathrm{CaCl}$, $1.0 \mathrm{~mm} \mathrm{MgSO}_{4}$, and $11.1 \mathrm{~mm}$ glucose. VTA VGluT2 neurons were identified by enhanced yellow fluorescent protein (eYFP) fluorescence. Cell attached recordings were obtained in the loose-patch configuration (Nunemaker et al., 2003). For cell-attached recordings, pipettes were filled with the following: $150 \mathrm{~mm} \mathrm{NaCl}, 10 \mathrm{~mm}$ HEPES, $10 \mathrm{~mm}$ glucose, $2.5 \mathrm{mM} \mathrm{CaCl}_{2}, 1.3 \mathrm{~mm} \mathrm{MgSO}_{4}$, and $3.5 \mathrm{~mm} \mathrm{KCl}$. Cells that exhibited spontaneous firing were included in the experiments. Cell attached firing rates were determined over the final $3 \mathrm{~min}$ of a 10-min drug wash-in and were normalized to a 3-min baseline. DNQX (10 $\mu \mathrm{M})$, APV (50 $\mu \mathrm{M})$, isoguvacine $(10 \mu \mathrm{M}$ or $50 \mu \mathrm{M})$, AMPA $(1 \mu \mathrm{M})$ and NMDA $(10 \mu \mathrm{M})$, and bicuculline $(10 \mu \mathrm{M})$ were bath applied. All recordings were performed in the presence of $1 \mu \mathrm{M}$ strychnine to block glycine receptors. All salts and strychnine hydrochloride were purchased from Sigma-Aldrich. DNQX, APV, isoguvacine, NMDA, and bicuculline were purchased from Tocris Biosciences.

\section{Statistical analyses}

Statistical analyses were performed in SPSS (IBM) or Prism (GraphPad). For the reward task, the average percent of RewCS+ and RewCS- trials that mice entered the reward port during the first $3 \mathrm{~d}$ of training and last $3 \mathrm{~d}$ of training was analyzed for each sensor group using repeated measures ANOVA. Pairwise comparisons with Sidak correction followed significant cue $\times$ time interaction to compare percent reward port entries following RewCS + and RewCS- over training. For the aversion task, the average number of seconds freezing in response to the ShkCS + and ShkCS- during the first session with no foot shock conditioning and the final session with foot shock conditioning was analyzed using repeated measures ANOVA. Manual freezing analysis was obtained and averaged across three blind scorers and was defined as the absence of alternating limb movements and non-postural head movements. Pairwise comparisons with Sidak correction followed significant cue $\times$ time interaction to compare time freezing following ShkCS + and ShkCS- over training.

For neurotransmitter sensor and calcium imaging, normalized $\mathrm{dF}$ ( $z$ score) of neural activity was analyzed separately for each sensor (iGluSnFR, iGABASnFR, GCaMP6m). Activity -6 to $-3 \mathrm{~s}$ before each cue was used to establish a baseline for their forthcoming cue and outcome (Root et al., 2010). Cue-related activity was examined 0-2 s following cue onset. Reward-related activity was examined during the duration of reward delivery, 8.5-10 s following the RewCS+, and this timing was applied for non-reward activity following the RewCS- as well as for error-related activity following the RewCSe cues. In the lick task, reward-related activity was examined 0-2 s following the first lick of at least a two-lick bout that resulted in reward. Non-reward-related activity was examined 0-2 s following the first lick of at least a two-lick bout that did not result in reward. Shock-related activity was examined during and following the 0.5-s shock duration, 9.5-11.5 s following the ShkCS+, and this timing was applied for the non-shock activity following the ShkCS-. iGABASnFR signaling typically decreased from baseline (normalized $z$ score $<0$ ) for cues and outcomes. Therefore, the minimum baseline value during the baseline epoch was compared with the minimum cue value during the cue epoch, and with the minimum outcome value during the outcome epoch (reward, shock, etc.). GCaMP signaling uniformly increased for all cues and outcomes (normalized $z$ score $>0$ for all mice). Therefore, the maximum baseline value was compared with the maximum cue and outcome values. For the cued licking task, the maximum baseline value ( -6 to $-3 \mathrm{~s}$ before the first lick during $\mathrm{CS}+$ or CS error) was compared with the maximum value during 0-2 $\mathrm{s}$ following the first lick during CS+ or CSe. iGluSnFR signaling was increased by reward-related cues but either increased or decreased at reward. Because of the different patterns in reward-related activity within the iGluSnFR group, cue-related increases (normalized $z$ score $>0$ for all mice) in activity were examined separately from rewardrelated activity. To examine cue-related activity, the maximum baseline value was compared with the maximum cue value using a paired $t$ test. We next compared the reward-related activity separately in rewarddecreasing and reward-increasing iGluSnFR mice. The reward-increasing iGluSnFR subgroup compared the maximum baseline value with the maximum reward value using a paired $t$ test (normalized $z$ score at reward $>0$ ). The reward-decreasing iGluSnFR subgroup (normalized $z$ score $<0$ at reward) compared the minimum baseline value with the minimum reward value using a paired $t$ test. Unless otherwise stated, all analyses of neuronal activity first consisted of repeated measures ANOVA examining differences between baseline, cue, and outcome. If the assumption of sphericity was not met (Mauchley's test), the Greenhouse-Geisser correction was used. Following up significant main effects of epoch, we prioritized determining differences in neuronal activity between baseline and cue, or baseline and outcome. Therefore, 
simple contrast tests were used. In specific instances of testing planned differences between events (i.e., differences between reward-delivered and reward-omitted conditions), paired $t$ tests were used.

Electrophysiological data were analyzed using Sutterpatch software and GraphPad Prism. Cell-attached recordings of percent spontaneous firing rate from baseline in the presence of DNQX/ APV, bicuculline, AMPA/NMDA, and isoguvacine were analyzed using one sample $t$ tests. The coefficient of variation was calculated by dividing the standard deviation of interspike intervals by the mean of interspike intervals during 1 min epochs either immediately before or $10 \mathrm{~min}$ after drug application.

\section{Data availability}

All custom MATLAB photometry scripts are publicly available at https://www.root-lab.org/code. Other relevant data are available from the corresponding author following reasonable request.

\section{Results}

\section{Pavlovian reward task}

Behavioral and neural data were collected from VGluT2::Cre mice expressing Cre-dependent iGABASnFR (to detect GABA release onto VTA VGluT2 neurons), iGluSnFR (to detect glutamate release to VTA VGluT2 neurons), or GCaMP6m (to detect changes in intracellular calcium of VTA VGluT2 neurons) using fiber photometry. Mice in each cohort initially trained on a Pavlovian reward paradigm where a RewCS + cue signaled forthcoming reward and co-terminated with the delivery of sucrose reward. Prior experimentation established that approximately half of VTA VGluT2 neurons change firing rates when an expected reward is omitted, suggesting VTA VGluT2 neurons can be sensitive to the anticipation of reward (Root et al., 2018). To examine changes in glutamate, GABA, or intracellular calcium during the presence or absence of an expected reward, 10\% of RewCS+ trials resulted in the omission of reward, termed error trials (RewCSe). Mice were concurrently trained to associate a neutral cue (RewCS-) with the absence of sucrose delivery. After each mouse reached the established behavioral criterion (see Materials and Methods) they were recorded fiber photometrically.

\section{GABA inputs to VTA VGluT2 neurons during Pavlovian reward}

Over the course of training, iGABASnFR mice (Fig. 1A) learned to increase reward-port entries depending on the cue presented, $F_{(1,18)}=14.5, \quad p=0.00128$. Reward port entries significantly increased in response to the RewCS+ on the last $3 \mathrm{~d}$ of training compared with the first $3 \mathrm{~d}$ of training, $p<0.0001$. There were no statistically significant changes in reward port entries for RewCS- cues over training, $p=0.68$ (Fig. 1B). iGABASnFR activity, which captures GABAergic transmission to VTA VGluT2 neurons, was significantly modulated by reward trials, $F_{(2,22)}=60.02, p=1.23 \times 10^{-9}$. iGABASnFR activity was significantly decreased at the RewCS + cue, $t_{(11)}=2.3776, p=0.0183$ and GABA signaling decreased at reward presentation, $t_{(11)}=$ 9.8778, $p=4.179 \times 10^{-7}$ when compared with baseline (Fig. 1C$E)$. Additionally, there was no significant correlation between individual mouse reward port entry behavior and GABASnFR signaling, $r=0.4829, p=0.1118$. Performance in this task was defined by the $\%$ of successful head entries into the magazine when the RewCS + was presented. iGABASnFR activity was also significantly modulated by reward omission trials, $F_{(2,22)}=21.29$, $p=7.169 \times 10^{-6}$. During RewCSe trials when expected sucrose reward was omitted, iGABASnFR activity significantly decreased at the time of the expected reward, $t_{(11)}=6.0945, p=3.891 \times$
$10^{-5}$, suggesting that GABA input to VTA VGluT2 signals reward anticipation and are not sensitive to reward omission (Fig. $1 F-H)$. For RewCS- trials that predicted no reward outcome, iGABASnFR activity was not significantly different from baseline, $F_{(2,22)}=2.650, p=0.093$ (Fig. $\left.1 I-K\right)$.

\section{Glutamate inputs to VTA VGluT2 neurons during Pavlovian reward}

iGluSnFR mice (Fig. 2A) learned to emit head entries into the reward port over training depending on the cue presented, $F_{(1,22)}=34.11, \quad p=0.00000708$. Mice significantly increased reward port entries in response to the RewCS + between the first and last $3 \mathrm{~d}$ of training, $p<0.0001$, indicating that mice learned to increase responding for reward trials (Fig. 2B). RewCS- head entries did not change over training, $p=0.99$. iGluSnFR activity significantly increased following RewCS + cues, $t_{(11)}=2.266$, $p=0.0446$. However, in contrast to the decreased iGABASnFR activity at reward, subsets of iGluSnFR sensor mice showed divergent iGluSnFR activity at reward (Fig. $2 C-E$ ). One subset of iGluSnFR mice $(n=5)$ significantly increased activity at reward, $t_{(4)}=3.754, p=0.019$. A different subset of iGluSnFR mice $(n=7)$ significantly decreased activity at reward, $t_{(6)}=-6.43$, $p=0.000668$. Implants spanned anteroposterior and subdivision (rostral linear, caudal linear, interfascicular, parabrachial pigmented, and paranigral nuclei) aspects of the VTA and post hoc analysis revealed that fibers for iGluSnFR reward-increasing mice were significantly more lateral than reward-decreasing mice. The midpoint of iGluSnFR fiber placement along the mediolateral axis was $0.3 \mathrm{~mm}$. Within lateral iGluSnFR placements $(>0.3 \mathrm{~mm})$, four out of four iGluSnFR mice increased at reward. In contrast, within medial iGluSnFR placements $(<0.3$ $\mathrm{mm}$ ), one out of eight iGluSnFR mice increased at reward, with the remaining seven medial iGluSnFR mice decreasing at reward. The proportion of increasing iGluSnFR mice was significantly different between medial and lateral locations, Fisher's exact test, $p<0.05$. There were no significant differences between anterior/ posterior or dorsal/ventral placements, Fisher's exact test, $p>0.05$. Additionally, there were no significant differences in conditioning between divergent reward-related iGluSnFR activity profile groups. iGluSnFR reward groups discriminated between cues equivalently and received comparable training, as assessed by percent of reward port entry during the CS + using an unpaired $t$ test, $t_{(10)}=1.045, p=0.3207$. There were no significant correlations between reward port entry percentage and recorded iGluSnFR change at reward iGluSnFR reward-increasing mice, $r=0.4425, p=0.4555$, or iGluSnFR reward-decreasing mice, $r=0.1651, p=0.7235$. Performance in this task was defined by the $\%$ of successful head entries into the magazine when the RewCS+ was presented.

Mice with iGluSnFR decreases at reward did not show a significant change in neuronal activity from baseline during unexpected reward omission, $t_{(6)}=1.347, p=0.226$. However, mice with iGluSnFR increases at reward significantly increased activity at unexpected reward omission, $t_{(4)}=-5.358, p=0.00585$ (Fig. $2 F, G)$. The increased iGluSnFR activity during reward was not significantly different from the increase during reward omission, $t_{(4)}=1.208, p=0.2936$. This suggests that reward-increasing glutamate inputs to VTA VGluT2 neurons signal reward anticipation and may not process when a reward is omitted. Both groups of iGluSnFR mice showed no significant change in neuronal activity for neutral RewCS- trials, reward-increasing: $F_{(2,8)}=3.50$, $p=0.080$, reward-decreasing: $F_{(2,12)}=1.54, p=0.254$ (Fig. $2 H, I$ ). 
A

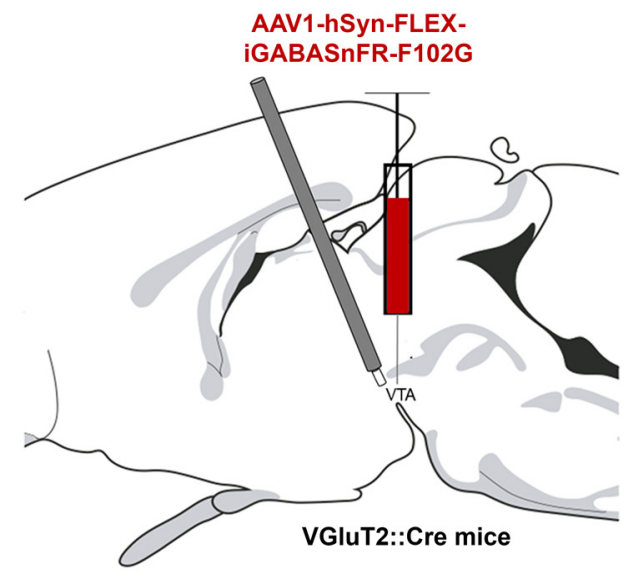

B

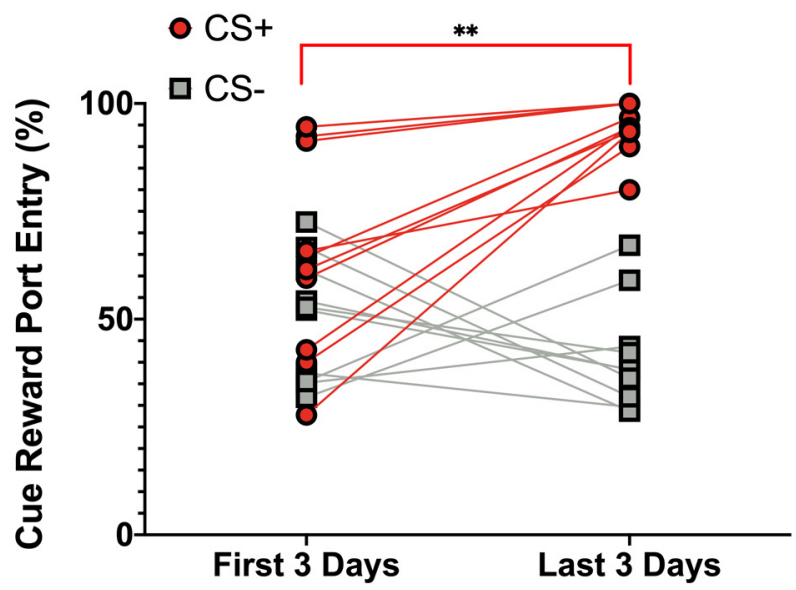

$\mathbf{E}$

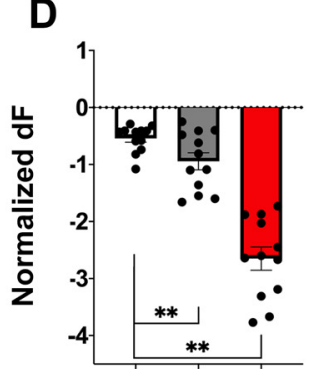

BL CS+ Rew

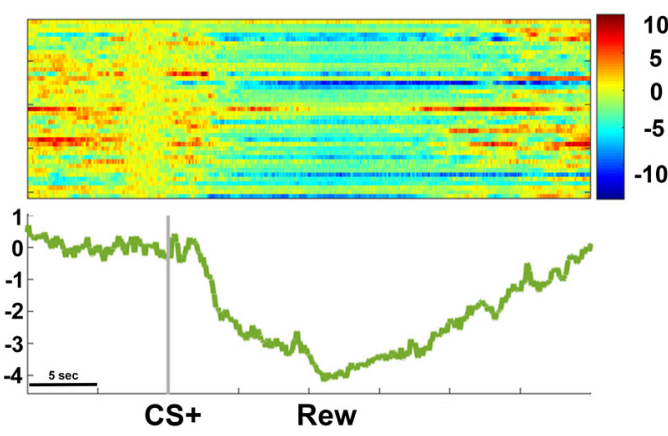

H

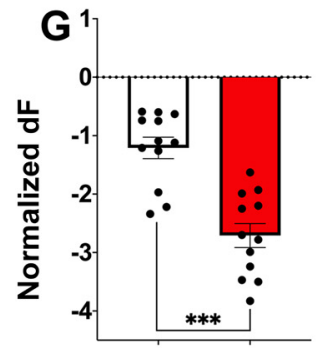

BL Omission
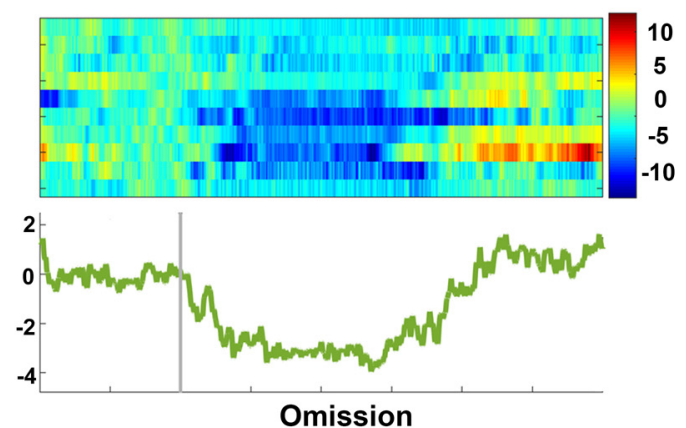

Omission

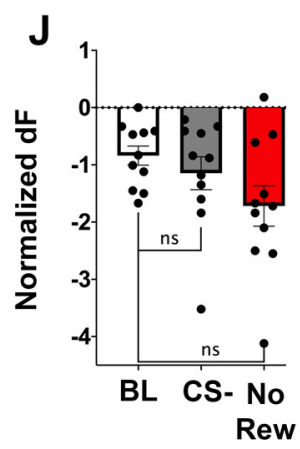

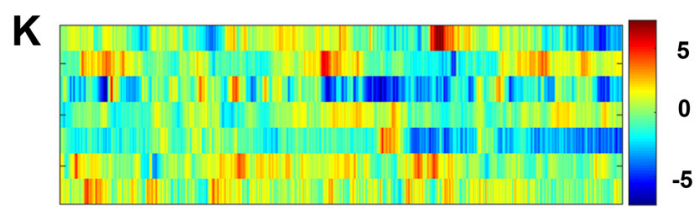

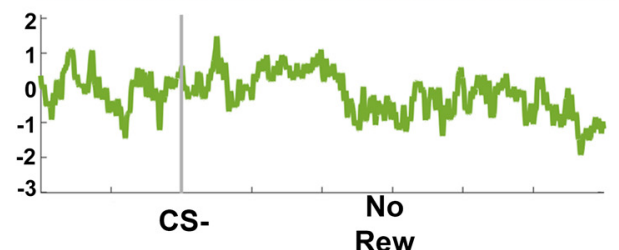

Figure 1. GABA input (iGABASnFR) to VTA VGluT2 neurons during Pavlovian reward. $A$, VGluT2::Cre mice were injected in the VTA with an AAV encoding Cre-dependent iGABASnFR and an optic fiber was implanted in the VTA. See fiber placements in Figure 6. B. Mice learned to discriminate between reward-predictive cues (CS+, red) and neutral cues (CS-, gray). $\boldsymbol{C}$, Normalized $z$ score (dF) for all iGABASnFR mice over time (group mean: solid line, SEM: shading). Decrease in GABA signaling at CS+ and sucrose presentation. $\boldsymbol{D}$, Normalized dF of CS+ and reward compared with baseline. $\boldsymbol{E}$, Sample trial-by-trial heat map and average trace from a representative iGABASnFR animal across reward trials. $\boldsymbol{F}$, Normalized dF for all iGABASnFR mice during reward error trials (group mean: solid line, SEM: shading). GABA input decreased from baseline at reward omission. $\boldsymbol{G}$, Normalized dF of reward omission compared with baseline. $\boldsymbol{H}$, Sample trial-bytrial heat map and average trace from a representative iGABASnFR mouse across error trials. $I$, Normalized dF for all iGABASnFR mice over time for neutral trials (CS-; group mean: solid line, 


\section{Pavlovian aversion task}

Following reward recordings, mice were trained on a Pavlovian foot shock paradigm in a separate context where a conditioned stimulus (ShkCS+) predicted foot shock and a neutral cue (ShkCS-) predicted no shock (Fig. $3 A$ ). We found that this behavioral procedure resulted in learned freezing behavior, training $\times$ cue interaction $F_{(1,6)}=22.34, p=0.00323$, that was increased in response to the ShkCS,$+ p<0.001$, and the ShkCS-, $p<0.01$. However, after conditioning the amount of time spent freezing was significantly longer in response to the ShkCS+ compared with the ShkCS-, $p<0.01$, indicating that mice learned to produce more extensive fear behavior in response to the shock-predicting cue (Fig. $3 B$ ). All mice within each sensor group received equivalent conditioning and were recorded fiber photometrically.

\section{GABA inputs to VTA VGluT2 neurons during Pavlovian aversion}

iGABASnFR activity was modulated by aversive stimuli trials, $F_{(2,24)}=6.478, p=0.0227$. iGABASnFR activity rapidly decreased following the ShkCS + cue, $t_{(12)}=4.555, p=0.00033$, and foot shock delivery, $t_{(12)}=3.1556, p=0.00414$ (Fig. $3 C$ ). Additionally, iGABASnFR activity was modulated by trials predicting the absence of footshock, $F_{(2,24)}=7.47, p<0.01$. iGABASnFR activity decreased following ShkCS- presentation, $F_{(2,24)}=7.468$, $p=0.00993$, but quickly returned to values not statistically different from baseline at the non-shock outcome, $t_{(12)}=-1.654$, $p=0.93805$ (Fig. 3D).

\section{Glutamate inputs to VTA VGluT2 neurons during Pavlovian aversion}

In contrast to the diverse responses of iGluSnFR activity to reward, iGluSnFR activity homogeneously increased in response to Pavlovian cues associated with footshock and footshock delivery in each iGluSnFR mouse. Increases in iGluSnFR activity did not statistically differ between glutamate sensor groups (reward increasing or reward decreasing) at any event (ShkCS+: $t_{(10)}=0.029, p=0.98$; footshock: $t_{(10)}=-1.69$, $p=0.12$; ShkCS-: $t_{(10)}=0.085, p=0.93$; non-shock outcome: $\left.t_{(10)}=-0.17, p=0.86\right)$. Therefore, iGluSnFR subgroup data were collapsed for within-subjects statistical comparisons. iGluSnFR activity was significantly modulated by aversive stimuli trials, $F_{(2,22)}=65.036, p=5.808 \times 10^{-10}$. iGluSnFR activity significantly increased following ShkCS + cues, $F_{(1,11)}=23.444$, $p=0.000518$, and following foot shock, $F_{(1,11)}=106.214, p=$ $5.466 \times 10^{-7}$ (Fig. $3 E$ ). iGluSnFR was also significantly modulated by trials predicting the absence of footshock, $F_{(2,22)}=18.972$, $p=1.627 \times 10^{-5}$. While iGluSnFR activity significantly increased following neutral ShkCS- cues, $F_{(1,11)}=23.494, p=0.000513$, there was no significant difference in activity from baseline at the nonshock outcome, $F_{(1,11)}=1.336, p=0.272$ (Fig. $3 F$ ).

\section{Neuronal activity of VTA VGluT2 neurons during Pavlovian reward}

To identify how VTA VGluT2 neurons integrate diverse neurochemical inputs into coherent neuronal activity patterns, we

SEM: shading). J, Normalized dF of CS- and non-reward compared with baseline. $\boldsymbol{K}$, Sample trial-by-trial heat map and average trace from a representative iGABASnFR mouse across neutral CS- trials that resulted in reward-port entry. Scale bars: $10 \mathrm{~s}(\boldsymbol{C}, \boldsymbol{F}, \boldsymbol{I})$ and $5 \mathrm{~S}(\boldsymbol{E}, \boldsymbol{H}$, K); ${ }^{*} p<0.05,{ }^{* *} p<0.01,{ }^{* *} p<0.001$, ns, not significant. recorded intracellular calcium dynamics within these neurons during the Pavlovian reward task. GCaMP mice (Fig. 4A) learned to emit head entries into the reward port over training depending on the cue presented, $F_{(1,12)}=35.31, p=0.00068$. Reward port head entries for RewCS + trials were significantly increased between the first and last $3 \mathrm{~d}$ of behavioral training, $p<0.0001$, indicating that mice learned to increase responding for reward trials (Fig. $4 B$ ). RewCS- head entries did not change over training, $p=0.56$. GCaMP activity was modulated by RewCS + trials, $F_{(2,12)}=11.35, p=0.00171$. VTA VGluT2 neuron activity was robustly increased following the presentation of the RewCS+, $F_{(1,6)}=28.63, p=0.0017$, and remained increased at reward delivery, $F_{(1,6)}=16.59, p=0.0065$ (Fig. $4 C, D$ ). Additionally, there was no significant correlation between successful reward entries following CS + presentation and neuronal activity, $r=0.0273$, $p=0.118$. Neuronal activity was also modulated by reward omission trials, $F_{(1,6)}=9.69, p<0.01$ (Fig. $4 E$ ). While GCaMP activity was significantly elevated over baseline at the time of reward omission, $F_{(1,6)}=13.2, p=0.0109$, we observed that the rewardrelated increase in GCaMP activity following reward presentation was not observed following reward omission. Direct comparison showed that reward omission activity was significantly decreased compared with reward presentation, $t_{(6)}=-2.73$, $p=0.033$. The discrepancy between GCaMP activity when reward was received versus when an expected reward was omitted suggests that VTA VGluT2 neuron activity discriminates omitted from received reward. Calcium signaling was not altered by RewCS- trials, $F_{(2,12)}=0.19, p=0.827$ (Fig. $4 F$ ).

To further examine the difference in VTA VGluT2 neuron calcium signaling between reward omission and reward receipt, we ran a separate cohort of GCaMP mice on a modified cued sucrose licking task. Mice in this paradigm earned sucrose reward by licking at a spout during the presentation of a tone/light cue. Once mice developed a steady pattern for active licking during cue presentations, as evidenced by an increase of $13.29 \pm 4.49 \%$ rewarded licks during the first day of training to $66.67 \pm 4.93 \%$ rewarded licks during the last day of training, we coded $20 \%$ error trials during the recording session, where the cue was presented but no sucrose was delivered from the spout following licks. The goal of this method was to examine whether the difference in error signal we previously recorded was because of a lack of reward consumption movements. When these mice were reordered fiber photometrically we did not find a significant difference in VTA VGluT2 neuron calcium signaling between reward and reward omission trials at lick onset (Fig. 4G).

\section{Neuronal activity of VTA VGluT2 neurons during Pavlovian aversion}

Given that iGluSnFR activity increased and iGABASnFR activity decreased during shock, we hypothesized that VTA VGluT2 neuronal activity would increase in response to an aversive outcome. VTA VGluT2 neuron activity was modulated by shock trials, $F_{(2,12)}=60.047, p=5.62 \times 10^{-7}$. GCaMP activity significantly increased following presentation of the ShkCS,$+ F_{(1,6)}=44.74$, $p=0.00054$, as well as foot shock, $F_{(1,6)}=80.44, p=0.00010$ (Fig. $4 H)$. Calcium signals were not significantly altered by ShkCStrials, $F_{(2,12)}=1.39, p=0.285$ (Fig. $4 I$ ).

\section{Changes in VTA VGluT2 neuron signaling during reward approach and movement}

To assess VTA VGluT2 neuron signaling during reward approach behavior we analyzed iGABASnFR, iGluSnFR, and GCaMP6m signals for the first head entry into the reward 

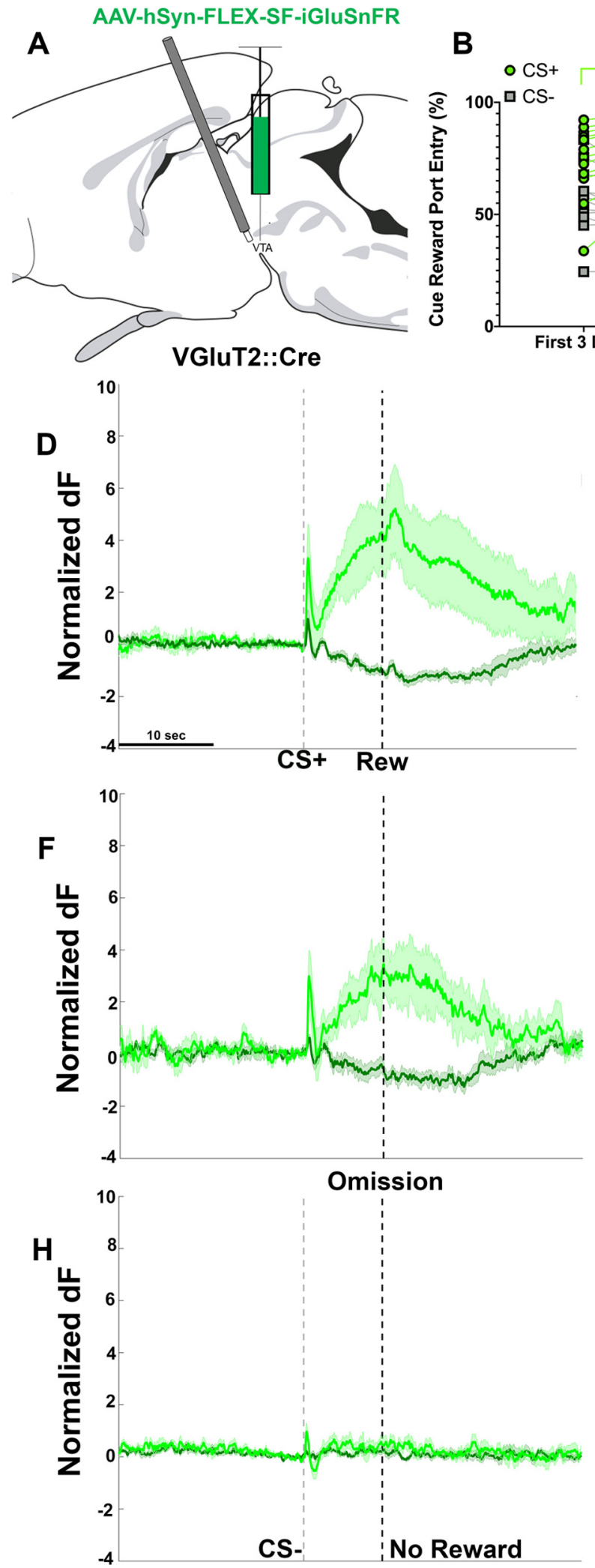
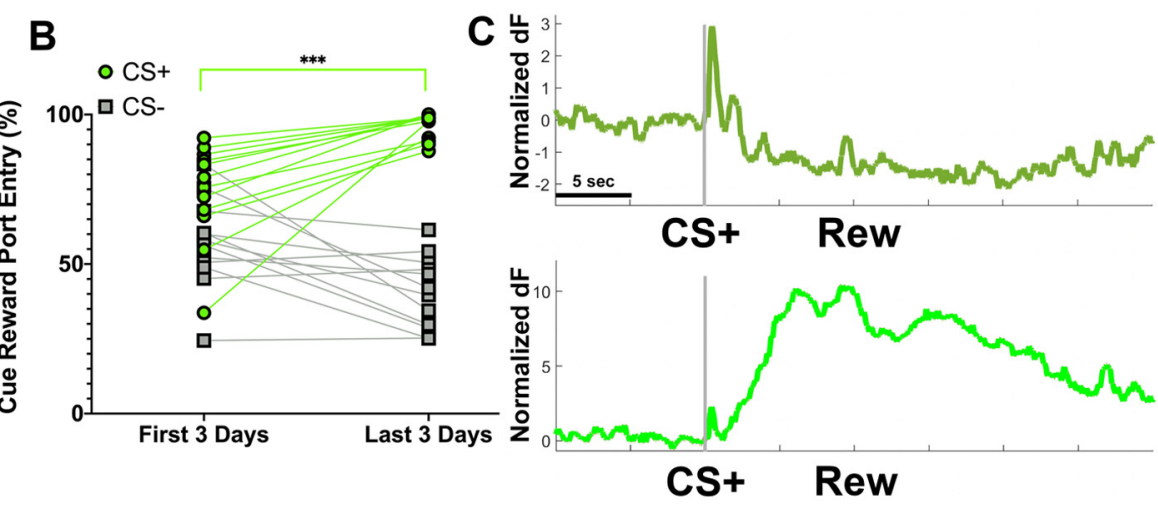

$\mathbf{E}$

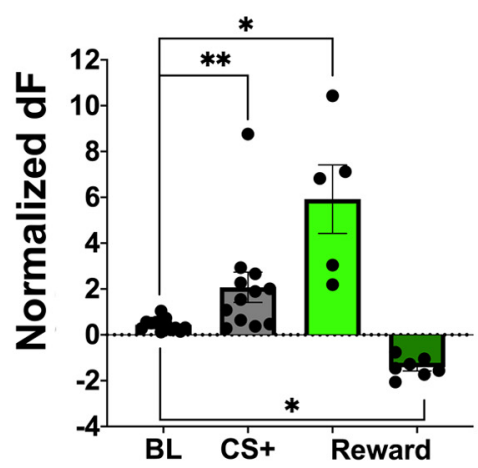

G
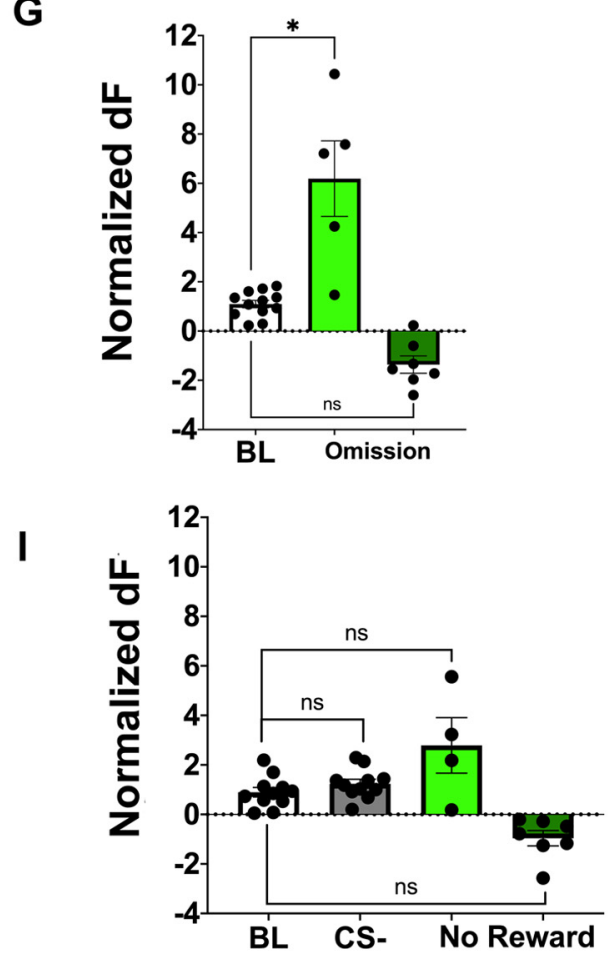

Figure 2. Glutamate input (iGluSnFR) to VTA VGluT2 neurons during Pavlovian reward. $A$, VGluT2::Cre mice were injected in the VTA with an AAV encoding Cre-dependent iGluSnFR and an optic was implanted in the VTA. B, Mice learned to discriminate between reward-predictive cues (CS+, green) and neutral cues (CS-, gray). C, top, Sample trace from representative mouse with an increase at $C S+$ and a decrease at reward ("reward-decreasing" iGluSnFR mouse, $n=7$ ). Bottom, Sample trace from representative mouse with an increase at $C S+$ but an increase at reward ("reward-increasing" iGluSnFR mouse, $n=5$ ). Scale bar: 5 s. D, Normalized dF of iGluSnFR subgroups during reward trials (group mean: solid line, SEM: shading). Reward-decreasing iGluSnFR activity increases at CS+ and decreases at reward (dark green). Reward-increasing iGluSnFR activity increases following at CS+ and reward (light green). Scale bar: 10 S (D, $\boldsymbol{F}, \boldsymbol{H}) . \boldsymbol{E}$, Normalized dF of $\mathrm{CS}+$ and reward compared with baseline. Dark green, reward decreasing; light green, reward increasing. $\boldsymbol{F}$, Normalized dF of iGluSnFR subgroups for reward error trials (group mean: solid line, SEM: shading). Dark green, reward decreasing; light green, reward increasing. Reward increaser mice (light green) did not show a significant difference between reward and unexpected reward omission, $t_{(4)}=1.208, p=0.2936$. $\mathbf{G}$, Normalized dF of reward omission compared with baseline. Dark green, reward decreasing; light green, reward increasing. $\boldsymbol{H}$, 
A
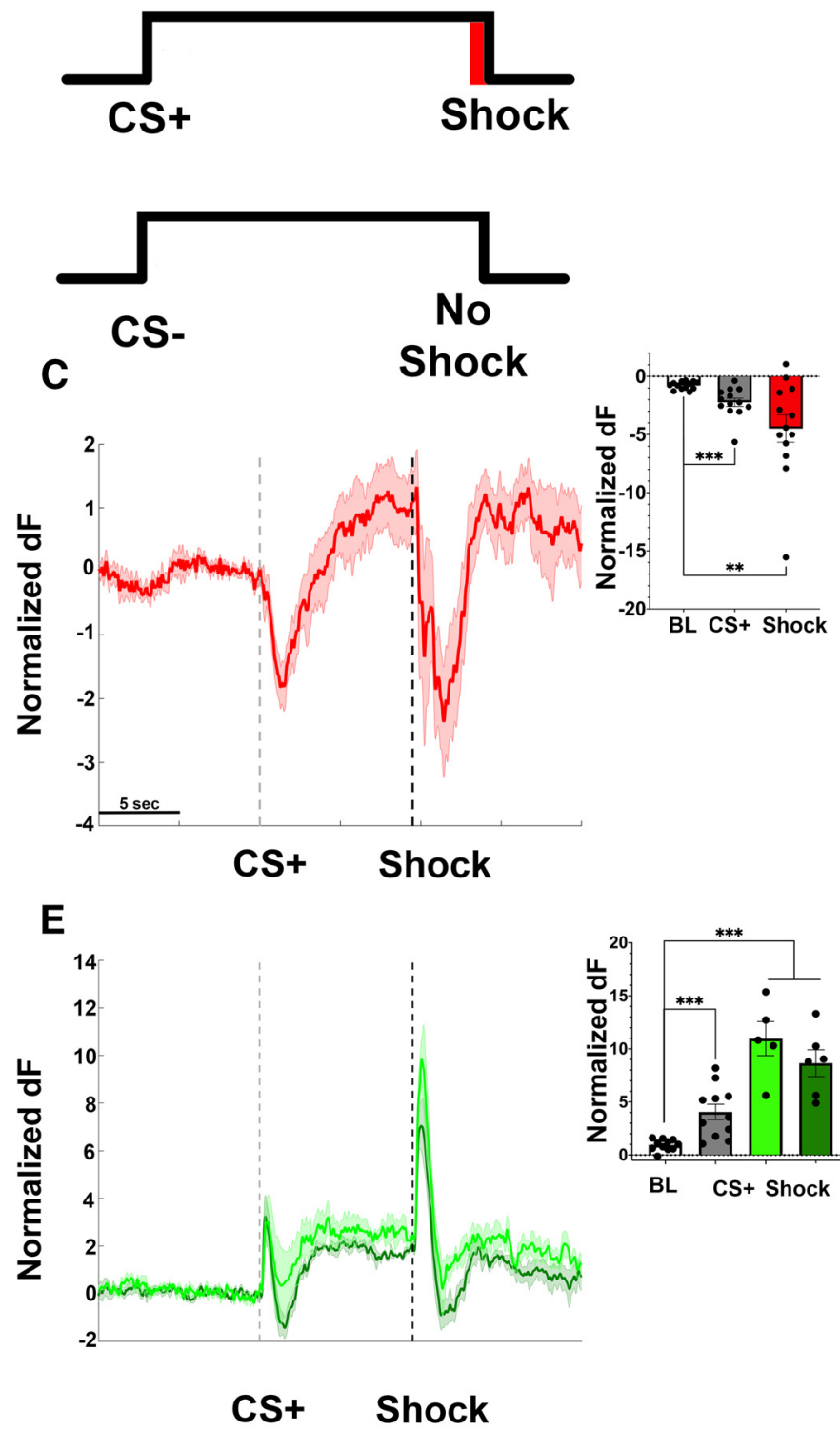

B

D
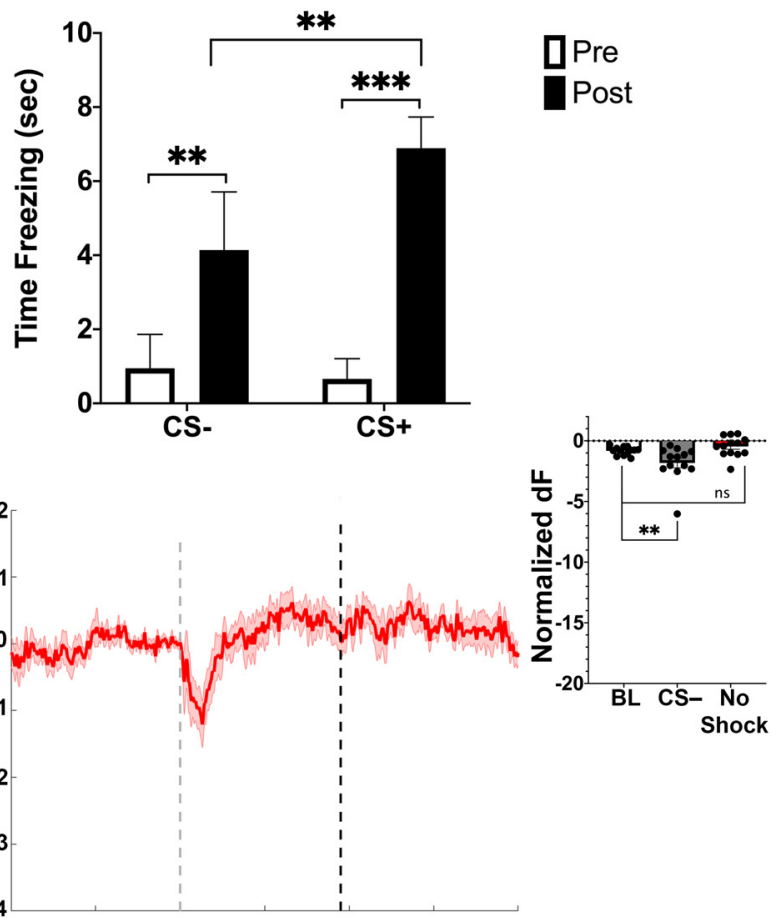

$\mathbf{F}$

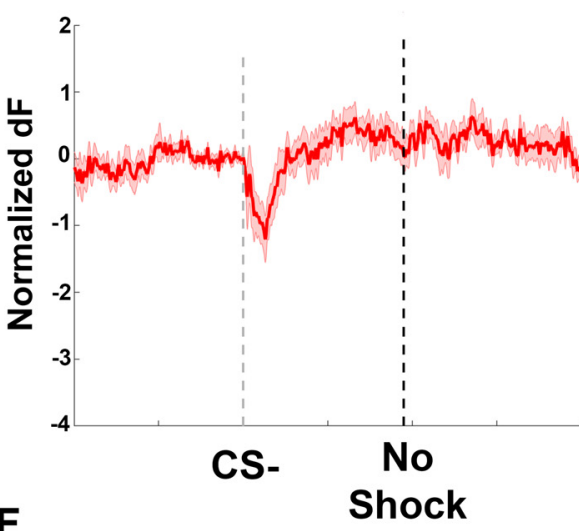

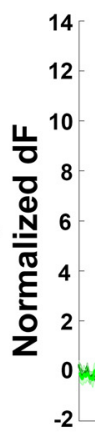

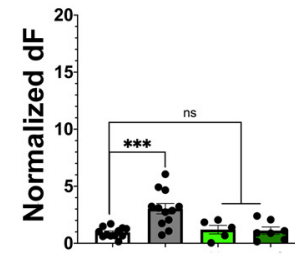

$\mathrm{BL}$ CS- No Shock

Figure 3. GABA and glutamate input to VTA VGluT2 neurons during Pavlovian aversion. $A$, Pavlovian aversion task. During training grid shock was paired with a $C S+$ tone and no shock was paired with a CS-. B, Time freezing for each cue pretraining or posttraining $(3 \mathrm{~d})$. Training increased freezing to each cue. Freezing was significantly higher following the $C S+$ compared with the CS-. C, Normalized iGABASnFR dF for CS + trials (group mean: solid line, SEM: shading). Inset, Significant decreases in iGABASnFR activity at CS + and shock compared with baseline. D, Normalized iGABASnFR dF for neutral trials (CS-; group mean: solid line, SEM: shading). Inset, Significant decrease in iGABASnFR activity at CS- but not non-shock outcome. $E$, Normalized iGluSnFR dF for CS + shock trials (group mean: solid line, SEM: shading; reward-increasing subgroup: light green; reward-decreasing subgroup: dark green). Inset, Significant increase in iGluSnFR activity at CS+ and shock compared with baseline. $\boldsymbol{F}$, Normalized iGluSnFR dF for neutral trials (CS-; group mean: solid line, SEM: shading; reward-increasing subgroup: light green; rewarddecreasing subgroup: dark green). Inset, Significant increase in iGluSnFR activity at CS- but no change for non-shock outcome. Scale bar: 5 s $(\mathbf{C}-\boldsymbol{F})$; ${ }^{* *} p<0.01$, ${ }^{* * *} p<0.001$, ns, not significant.

magazine following CS+ presentation, before reward delivery. These head entry data points are separable from reward entry trials described previously because they occurred before reward delivery. Additionally, to determine whether movement and reward-port entry changed VTA VGluT2 neuron signaling in the absence of cues or reward we analyzed iGABASnFR,

Normalized dF of iGluSnFR subgroups for neutral reward trials (CS-; group mean: solid line, SEM: shading). Dark green, reward decreasing; light green, reward increasing. I, Normalized $\mathrm{dF}$ of $\mathrm{CS}$ - and non-reward outcome compared with baseline. Dark green, reward decreasing; light green, reward increasing; ${ }^{*} p<0.05,{ }^{* *} p<0.01,{ }^{* *} p<0.001$, ns, not significant.
iGluSnFR, and GCaMP6m signaling during uncued reward magazine entries. For iGABASnFR signaling we found significant decreases in activity following the first reward-port entry after RewCS + presentation, $F_{(2,22)}=34.036, p=-1.07 \times 10^{-5}$ (Fig. $5 A$ ), and a significant decrease following uncued reward-port entries, $F_{(2,22)}=25.896, p=5.65 \times 10^{-5}$ (Fig. $5 B$ ). For iGluSnFR reward-increasing mice there was a significant increase in iGluSnFR signaling to VTA VGluT2 neurons following the first reward-port entry after RewCS + presentation, $F_{(2,8)}=14.042$, $p=0.0024$ (Fig. $5 C$ ), and during uncued reward-port entries, $F_{(2,8)}=12.752, p=0.0033$. iGluSnFR reward-decreasing mice did not show significantly changed activity following the first reward-port entry after RewCS + presentation, $F_{(2,12)}=3.251$, 
A
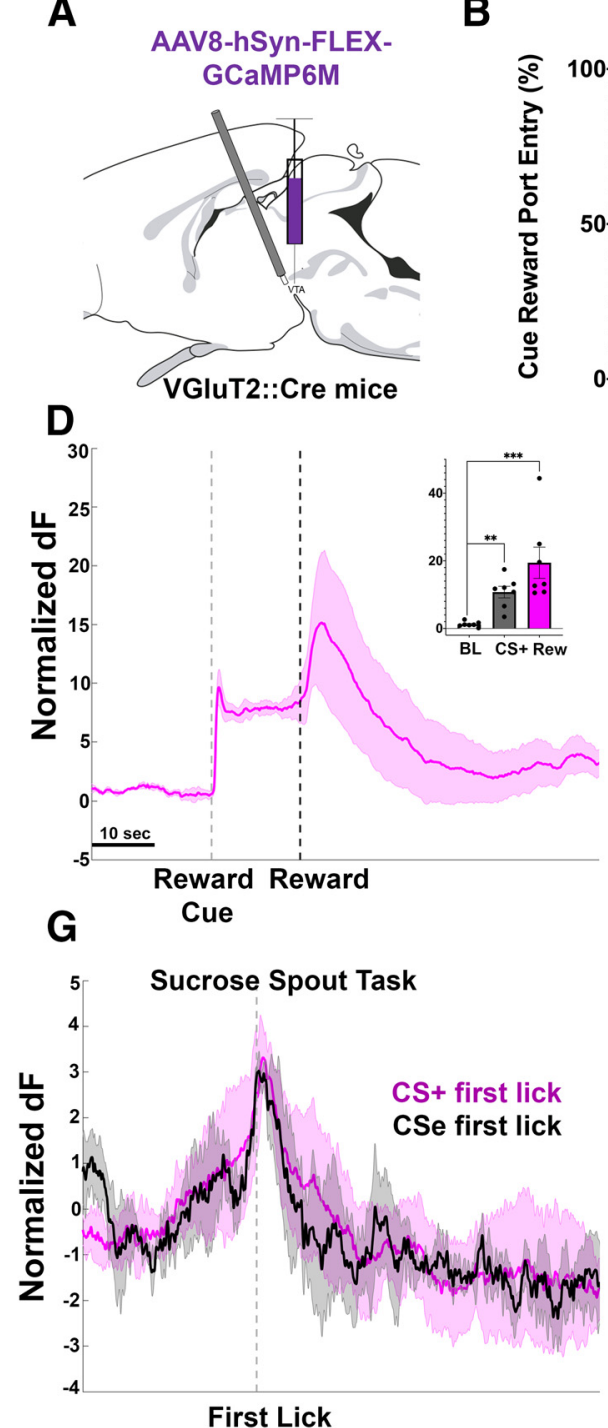

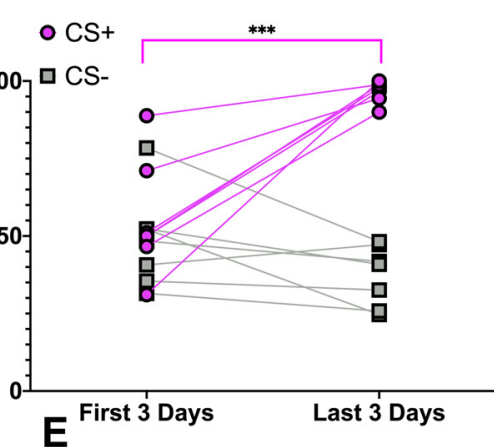

$E_{30}$
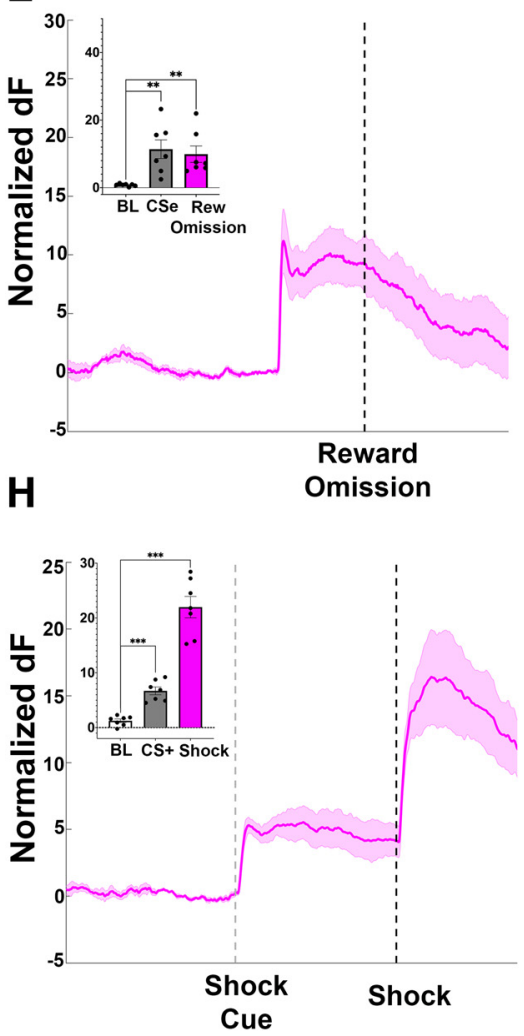
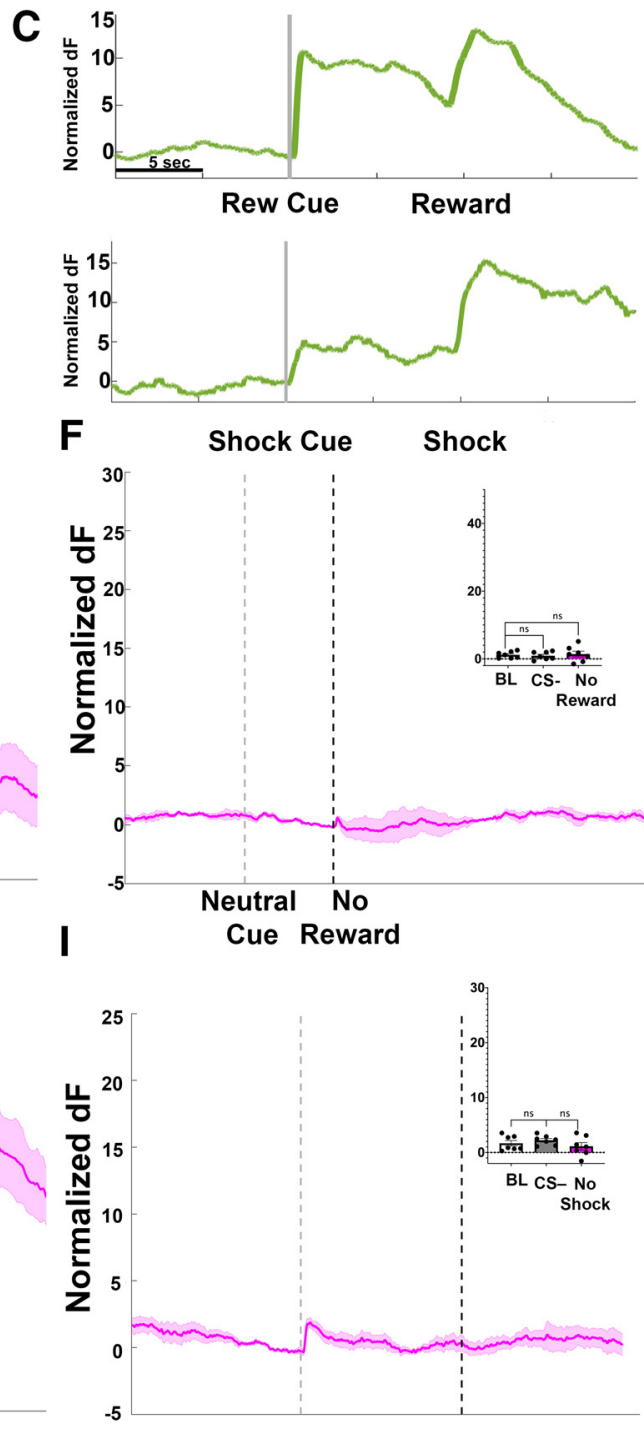

Figure 4. Neuronal activity of VTA VGluT2 neurons during Pavlovian reward and aversion. A, VGluT2::Cre mice were injected in the VTA with an AAV encoding Cre-dependent GCaMP6m and an optic fiber was implanted in the VTA. B, Mice learned to discriminate between reward-predictive cues (CS+, purple) and neutral cues (CS-, gray). C, top, Sample trace for GCaMP recording during Pavlovian reward, increase calcium signaling at $\mathrm{CS}+$ and sucrose reward. Bottom, Sample trace for GCaMP recording during Pavlovian aversion, increase at shock CS+ and shock. Scale bar: $5 \mathrm{~s}(\boldsymbol{D}-\boldsymbol{F})$. Normalized dF for reward trials (D). Inset, Comparison of baseline GCaMP activity to $(S+$ and reward, reward error trials $(\boldsymbol{E})$. Inset, Comparison of baseline GCaMP activity to CSe and reward omission, and neutral CS- trials (F). Inset, Comparison of baseline GCaMP activity to CS- and no reward delivery (group mean: solid line, SEM: shading). G, Normalized GCaMP activity between first lick at CS+ (purple line) and CSe (black line). $\boldsymbol{H}$, Normalized GCaMP dF for shock trials (group mean: solid line, SEM: shading). Inset, Significant increase in GCaMP activity at CS+ and shock compared with baseline. I, Normalized GCaMP dF for neutral trials (CS-; group mean: solid line, SEM: shading). Inset, No significant change in GCaMP activity during CS- trials compared with baseline. Scale bar: $10 \mathrm{~s}(\boldsymbol{D}-\boldsymbol{l}){ }^{* *} p<0.01,{ }^{* * *} p<0.001$, ns, not significant.

$p=0.116$, or for uncued magazine entries, $F_{(2,12)}=2.914$, $p=0.093$ (Fig. 5D). Recorded GCaMP signaling revealed a significant increase in intracellular calcium following the first rewardport entry after RewCS + presentation, $t_{(6)}=12.76, p<0.0001$ (Fig. 5E) and for uncued reward-port entries during the intertrial interval, $t_{(6)}=3.944, p=0.007$ (Fig. $5 F$ ). Fiber optic placement and viral expression was confirmed for all sensors (iGABASnFR, iGluSnFR, GCaMP6) for all mice. Mice with fiber optics that recorded sensors outside of the VTA were removed before analysis (Fig. 6).

Changes in firing of VTA VGluT2 neurons by glutamate and GABA receptor modulation

Our results indicate that glutamate and GABA inputs to VTA VGluT2 neurons are dynamically regulated by reward and aversion-based learned cues and outcomes. However, it is unclear how glutamate and GABA affect the firing of VTA VGluT2 neurons. To determine how glutamate and GABA affect the firing of VTA VGluT2 neurons, we fluorescently labeled VTA VGluT2 neurons by intra-VTA injection of Cre-dependent eYFP in VGluT2::Cre mice and performed cell-attached recordings of eYFP-expressing neurons in VTA-containing slices $(n=18$ cells, mean firing rate $12.64 \pm 2.80 \mathrm{~Hz}$, range $=1.8-$ $48.3 \mathrm{~Hz}$; Fig. $7 A$ ). Glutamate or GABA receptor antagonists or agonists were washed onto slices and spontaneous firing of VTA VGluT2 neurons was assessed. VTA VGluT2 neuron firing was significantly decreased following application of the AMPA and NMDA antagonists DNQX/APV, $t_{(5)}=5.64, p<0.01$, indicating that glutamate input maintains VTA VGluT2 basal firing. GABA-A receptor antagonism by application of bicuculline to 


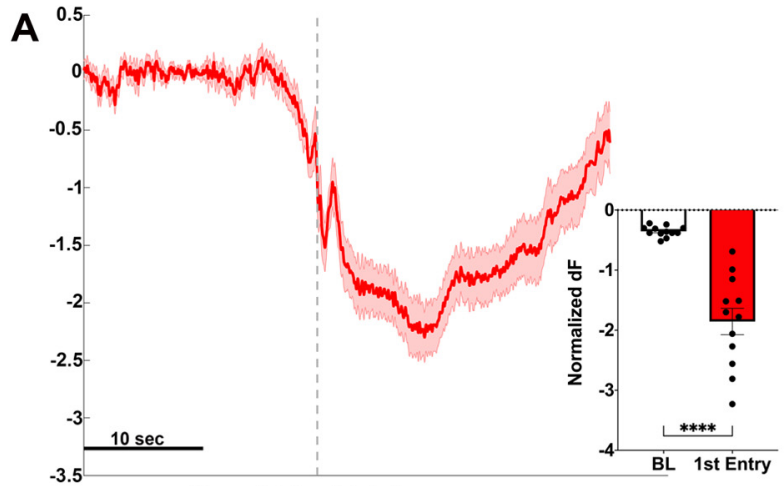

Cued Port Entry
B

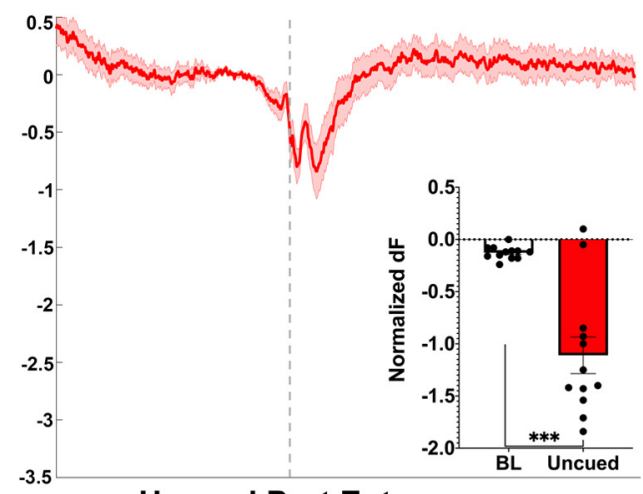

Uncued Port Entry
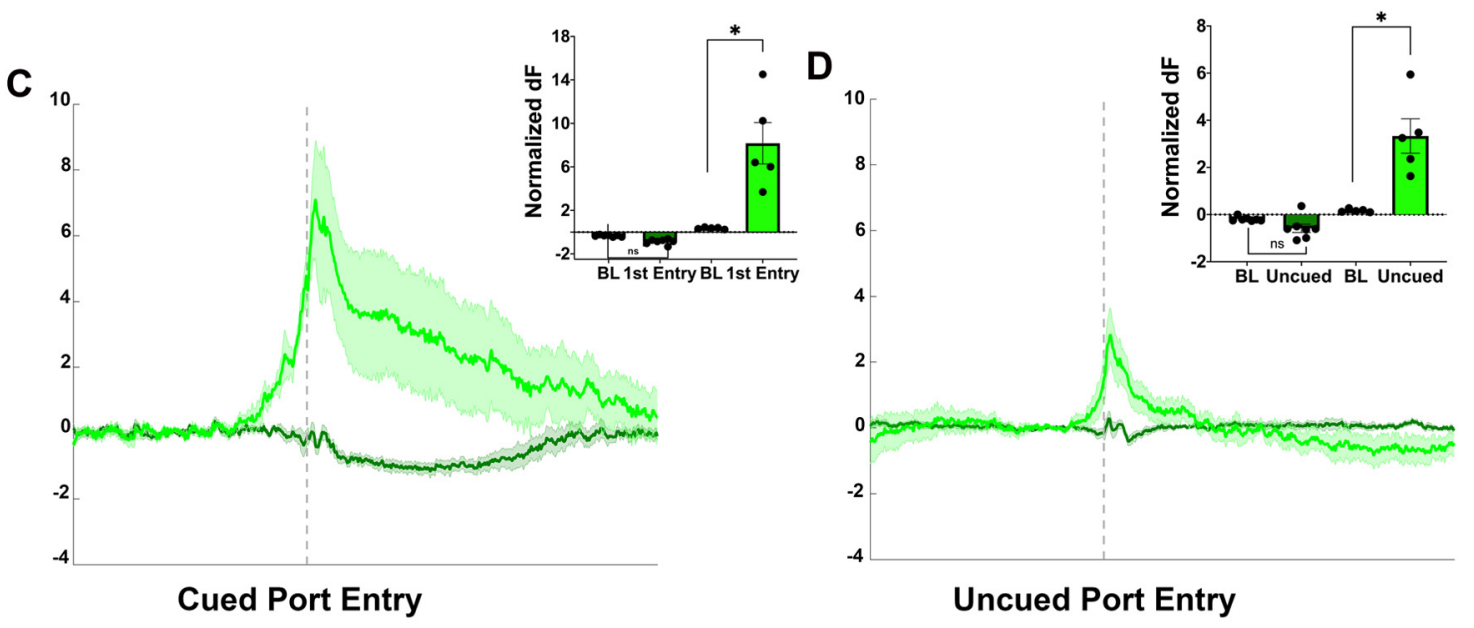

Uncued Port Entry
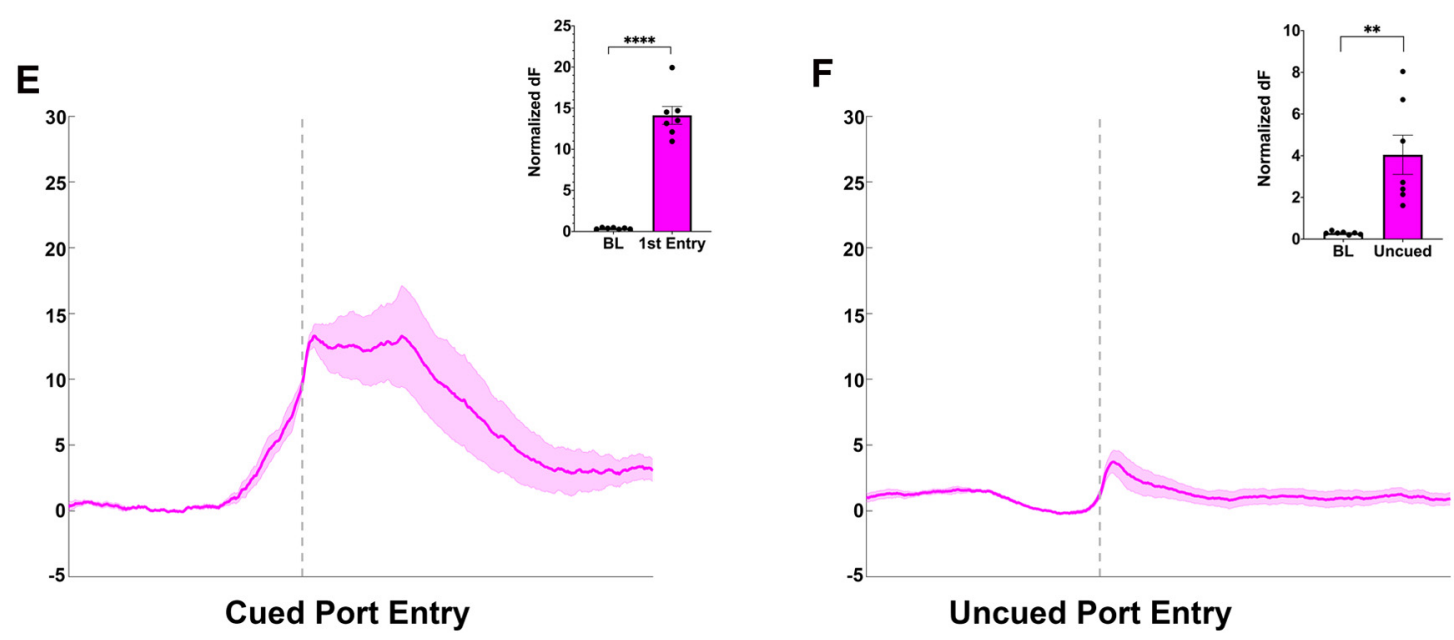

Figure 5. Motivation onset and movement-related signaling. $\boldsymbol{A}$, Normalized dF iGABASnFR photometry recordings for first entry into the reward magazine following RewCS+. Significant decrease following first entry compared with baseline $t_{(11)}=6.565, p<0.0001$. $B$, Normalized dF iGABASnFR recordings for uncued entry into the reward magazine. Significant decrease for uncued reward port entry $t_{(11)}=5.572, p=0.0002$. C, Normalized dF iGluSnFR (dark green-decreaser, light green-increaser) for first entry into the reward magazine. Significant change for first entry for reward decreasers $t_{(6)}=6.831, p=0.0005$ and reward increasers $t_{(4)}=4.046, p=0.0155$. $D$, Normalized dF iGluSnFR recordings for uncued entry into reward magazine. No significant change for reward decreaser $t_{(6)}=2.071, p=.0838$. Significant change for reward increaser $t_{(4)}=4.324, p=0.0124$. $E$, Normalized dF GCaMP recordings for first entry into reward port during RewCS +. Significant change at first entry $t_{(6)}=12.76, p<0.0001$. $\boldsymbol{F}$, Normalized dF GCaMP recordings for uncued entries in the reward magazine. Significant change for uncued entries $t_{(6)}=3.944, p=0.007$. Scale bar: $10 \mathrm{~s}(\boldsymbol{A}-\mathrm{E}) .{ }^{*} p<0.05,{ }^{* *} p<0.01,{ }^{* * *} p<0.001,{ }^{* * * *} p<0.0001$, ns, not significant.

VTA VGluT2 neurons did not significantly change firing rate $t_{(6)}=1.95, p=0.09$ (Fig. $7 B, C$ ). This result was contrary to our initial hypothesis that VTA VGluT2 neurons would be disinhibited by GABA-A receptor blockade. VTA VGluT2 neuron firing was significantly increased following application of AMPA/
NMDA, $t_{(4)}=3.129, p=0.035$, but did not significantly change firing following application of the GABA-A receptor agonist isoguvacine at $10 \mu \mathrm{M}, t_{(3)}=2.954, p=0.08$. A higher concentration of isoguavacine at $50 \mu \mathrm{M}$ significantly reduced firing, $t_{(5)}=5.316$, $p=0.003$ (Fig. $7 D, E$ ). Three-minute time courses were collected 

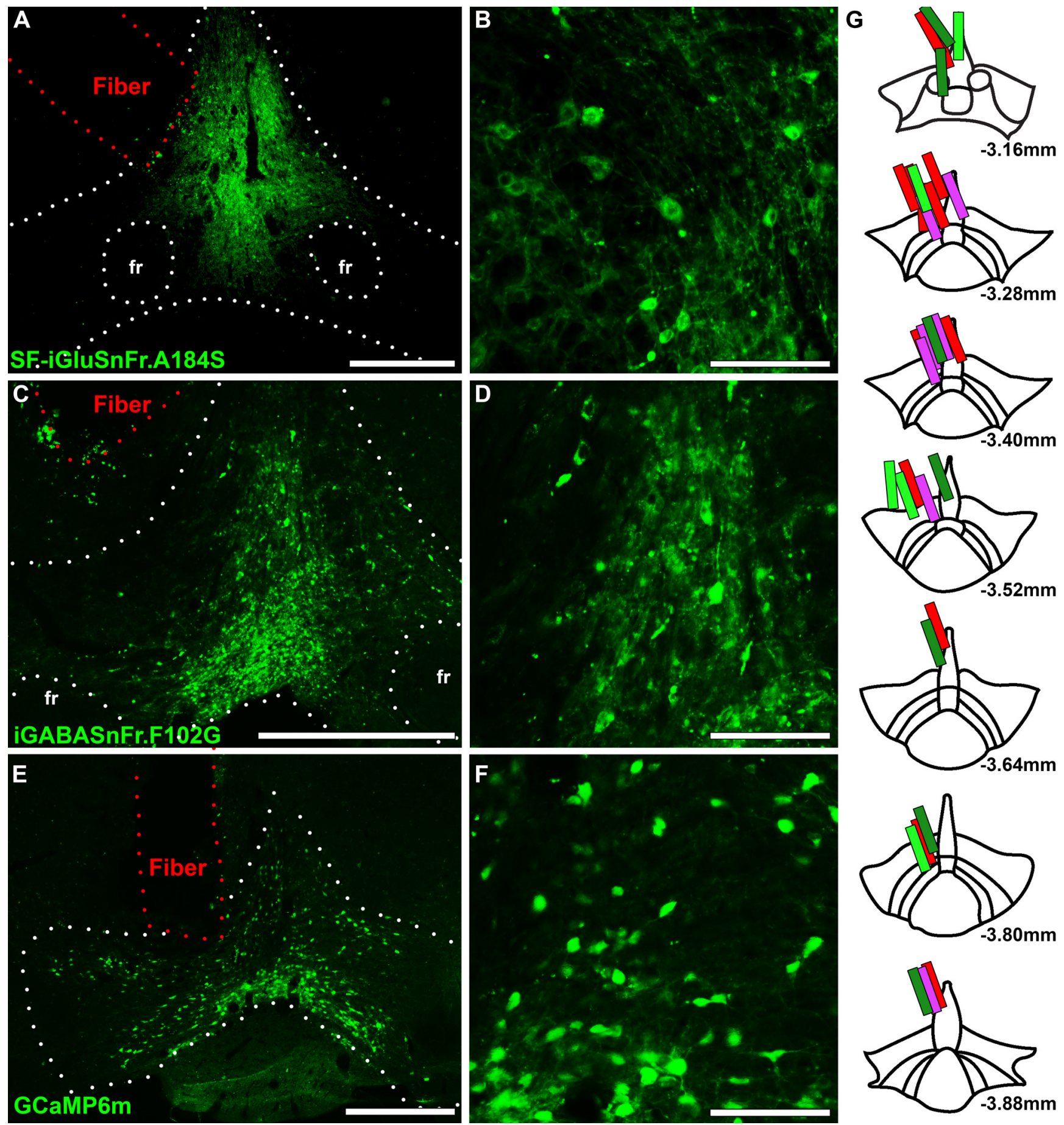

Figure 6. Topography of viral/fiber implant locations for all sensors. $\boldsymbol{A}, \boldsymbol{B}$, Example iGluSnFR cellular expression within VTA VGluT2 neurons in low $(\boldsymbol{A})$ and high $(\boldsymbol{B})$ magnification. $\boldsymbol{C}$, $\boldsymbol{D}$, Example iGABASnFR cellular expression within VTA VGluT2 neurons in low $(\boldsymbol{C})$ and high $(\boldsymbol{D})$ magnification. $\boldsymbol{E}, \boldsymbol{F}$, Example GCaMP cellular expression within VTA VGluT2 neurons in low $(\boldsymbol{E})$ and high $(\boldsymbol{F})$ magnification. $\boldsymbol{G}$, Fiber localizations. Light green, iGluSnFR reward increasing subgroup; dark green, iGluSnFR reward decreasing subgroup; red, iGABASnFR; purple, GCaMP. Number refers to anteroposterior position from bregma $(\mathrm{mm})$. Scale bars: $250 \mu \mathrm{m}(\boldsymbol{A}, \boldsymbol{C}, \boldsymbol{E})$ and $100 \mu \mathrm{m}(\boldsymbol{B}, \boldsymbol{D}, \boldsymbol{F})$. fr, fasciculus retroflexus.

for each agonist/antagonist wash condition to determine changes in firing from baseline (Fig. $7 F-J$ ). To assess whether manipulations of GABAergic or glutamatergic signaling affected the regularity of spiking, we calculated the coefficient of variation $(\mathrm{CV})$ of the interspike intervals following treatment with DNQX/APV (pre: $0.19 \pm 0.09$, post: $0.18 \pm 0.05, t_{(5)}=0.13, p=0.90$ ), bicuculline (pre: $0.23 \pm 0.08$, post: $0.20 \pm 0.07, t_{(5)}=0.811, p=0.47$ ), AMPA/NMDA (pre: $0.28 \pm 0.09$, post: $0.43 \pm 0.17, t_{(4)}=0.61$, $p=0.58$ ), and isoguvacine $10 \mu \mathrm{M}$ (pre: $0.22 \pm 0.08$, post: $\left.0.31 \pm 0.16, t_{(4)}=1.025, p=0.41\right)$. No significant changes in coefficient of variance were found, indicating that there was no change in the regularity of spiking with any of the four treatments (Fig. $7 K$ ). Taken together, these results indicate that glutamate is a strong regulator of increasing or decreasing neuronal activity of VTA VGluT2 neurons. In contrast, while GABA inputs acting at GABA-A receptors are capable of inhibiting VTA VGluT2 neuron firing, blockade of GABA-A activity was insufficient to increase VTA VGluT2 neuron basal firing rates. 
A AAV8-EF1a-DIO-eYFP

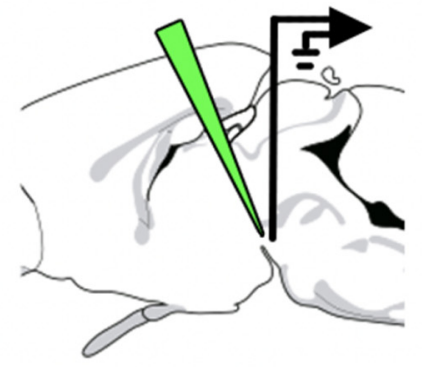

VGIuT2::Cre Mice
B

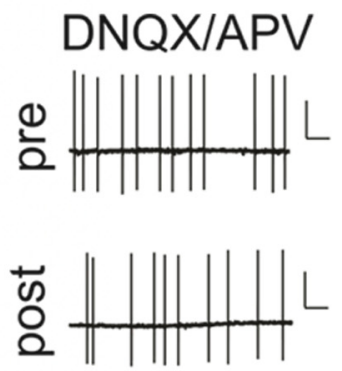

C

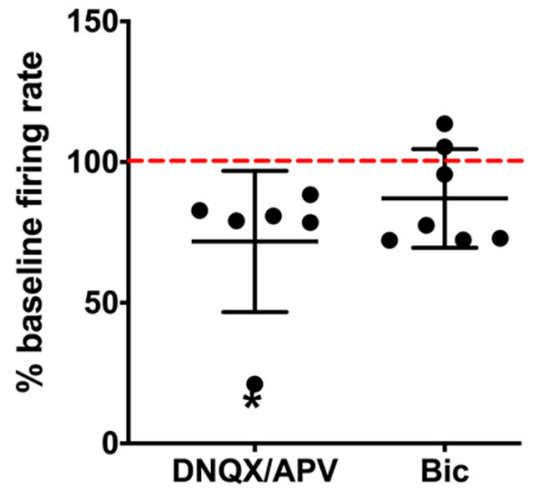

D
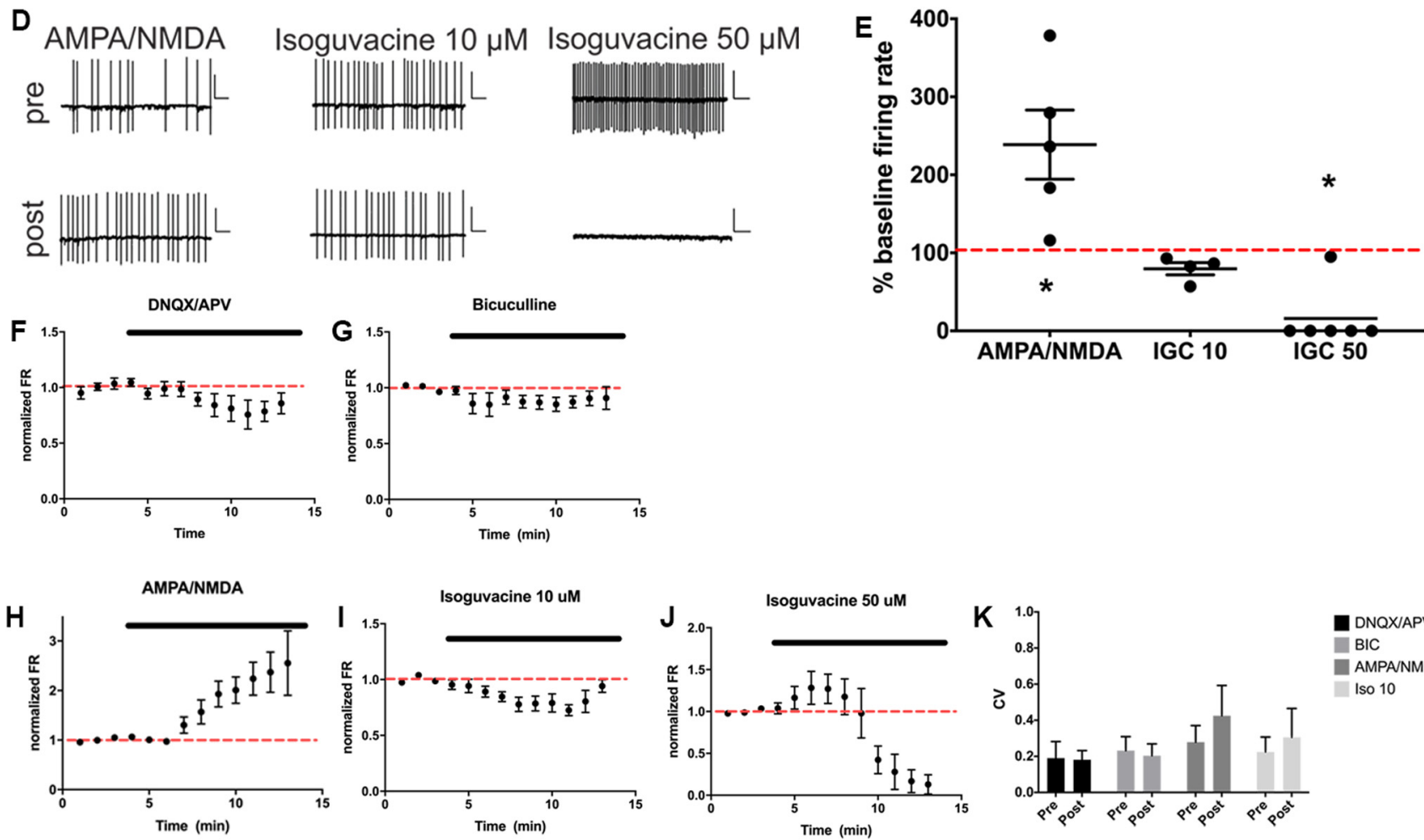

Figure 7. VTA VGluT2 neuron firing following GABA/Glutamate receptor agonism and antagonism. $\boldsymbol{A}$, VGluT2::Cre mice were injected in the VTA with an AAV encoding Cre-dependent eYFP. eYFP-expressing cells were recorded ex vivo in whole-cell or cell-attached mode. $\boldsymbol{B}, \boldsymbol{C}$, Both AMPA/NMDA (DNQX/APV) and GABA-A (bicuculline) receptor antagonists reduced baseline firing in VTA VGluT2 neurons. C, Quantification for each recorded cell following DNQX/APV or bicuculline compared with baseline firing rate. D, Glutamate receptor agonists (AMPA/NMDA) increase firing in VTA VGluT2 neurons, GABA-A receptor agonist (isoguvacine at $10 \mu \mathrm{m}$ ) had no significant effect but significantly reduced firing at $50 \mu \mathrm{m}$ concentration. $\boldsymbol{E}$, Quantification for each recorded cell following AMPA/NMDA or isoguvacine compared with baseline firing. Time course for electrophysiological recordings. $\boldsymbol{F}$, Normalized firing rate for VTA VGluT2 neurons following AMPA/ NMDA agonist over $15 \mathrm{~min}$. G, Normalized firing rate for VTA VGluT2 neurons following DNQX/APV over 15 min. $\boldsymbol{H}$, Normalized firing rate for VTA VGluT2 neurons following $10 \mu$ M isoguvacine over $15 \mathrm{~min}$. I, Normalized firing rate for VTA VGluT2 neurons following $50 \mu \mathrm{m}$ isoguvacine over $15 \mathrm{~min}$. J, Normalized firing rate for VTA VGluT2 neurons following bicuculline over 15 min k) coefficient of variation for interspike intervals during the last minute of the baseline and after 10 min of drug wash-on; ${ }^{*} p<0.05$. Scale bars: $200 \mathrm{ms,} 0.5 \mathrm{mV}$.

\section{Discussion}

Slightly over a decade ago the cellular landscape of the VTA expanded to include populations of neurons that express VGluT2, a molecular marker for neurons that accumulate glutamate into synaptic vesicles (Yamaguchi et al., 2007). Following their discovery, subpopulations of VGluT2 neurons have been categorically divided by their firing for rewarding and aversive stimuli (Root et al., 2018), projection targets (Taylor et al., 2014), and neurotransmitter co-release characteristics (Stuber et al., 2010; Root et al., 2014b; Mingote et al., 2017). Thus far, VTA VGluT2 neurons appear to have diverse roles in motivated behavior (Root et al., 2014a; Wang et al., 2015; Yoo et al., 2016).
Here, by using genetically encoded fluorescent reporters of glutamate and GABA signaling (Marvin et al., 2011, 2018, 2019), we aimed to identify how diverse rewarding and aversive information is neurochemically communicated to VTA VGluT2 neurons during motivated behavior.

We found that the pattern of glutamate inputs to VTA VGluT2 neurons during reward is not homogenous. One subpopulation of glutamate inputs increased while another decreased at reward delivery, as measured by iGluSnFR. Electrophysiological recordings from optogenetically-identified VTA VGluT2 neurons have also identified subtypes of neurons based on whether they increase or decrease firing rate during reward (Root et al., 2018). 
We found that the reward-increasing iGluSnFR population was located more laterally than the reward-decreasing population. Functional differences between medial and lateral VTA have also been identified in dopamine neurons. During early ethanol selfadministration training, ethanol consumption results in medial VTA dopamine neuron decreasing activity and lateral VTA dopamine neuron activity increasing (Liu et al., 2020). Medial and lateral VTA dopamine neurons also differ in their activity profiles and necessary roles in different types of ethanol relapse (Liu et al., 2020). Further, during extinction of cued fear, medial and lateral VTA dopamine neurons have different activity profiles and temporal roles in extinction (Cai et al., 2020). While our results suggest that VTA VGluT2 neurons may also have heterogenous function along the medio-lateral axis, not all medial glutamate recordings decreased at reward. Based on increasing or decreasing firing patterns of VTA VGluT2 neurons that follow reward (Root et al., 2018), we categorized iGluSnFR recordings into rewardincreasing and reward-decreasing groups. However, the recorded iGluSnFR patterns likely derive from a distribution that is influenced by an additional variable that at this time is not completely understood.

We hypothesize that different populations of glutamatergic inputs may reflect different aspects of motivated behavior. For instance, lateral hypothalamus $\rightarrow$ VTA glutamate input is relevant for innate defensive strategies (Barbano et al., 2020) while other glutamate inputs may be relevant for reward. Distinct glutamatergic projections to VTA VGluT2 neurons may partially mediate the diverse firing patterns of VTA VGluT2 neurons in response to reward. If this is the case, then it would be expected that increased glutamate input would correspond with enhanced firing and decreased glutamate input with a reduction in firing. We observed both effects, activating glutamate receptors was sufficient to increase VTA VGluT2 neuron firing and blocking glutamate receptors was sufficient to decrease VTA VGluT2 neuron firing ex vivo. We hypothesize that the functional heterogeneity of glutamate inputs to VTA VGluT2 neurons arises from circuitlevel differences within this subset of neurons. Such inputs may be sensitive to additional features of motivated behavior. For instance, a subset of VTA VGluT2 neurons increases firing during reward approach (Root et al., 2018), and we found that the reward increasing iGluSnFR group increased activity immediately before cued and uncued reward port entries. Further research will be necessary to test whether distinct populations of VTA VGluT2 neurons receive functionally separate glutamate inputs from unique brain regions (Faget et al., 2016), target different output brain regions (Taylor et al., 2014), or belong to a population of genetically unique VTA VGluT2 neurons that releases one or more neurotransmitters (Morales and Root, 2014; Root et al., 2014b, 2020; Mingote et al., 2017).

In contrast to glutamate inputs, GABAergic inputs to VTA VGluT2 neurons, measured by iGABASnFR, showed decreased activity in response to reward. To assess how VTA VGluT2 neurons integrate glutamate, GABA, and other inputs into a coherent neuronal activity pattern, we performed GCaMP recordings of VTA VGluT2 neurons in the same behavioral paradigm. Despite a heterogeneity in reported firing within these cells at reward (Root et al., 2018), and our demonstration of diverse patterns of glutamate inputs to these cells at reward, GCaMP recordings showed homogenously increased activity during reward. It is possible that integrating glutamate and GABA input at the reward event requires increased calcium signaling. Alternatively, because our GCaMP recordings were measured fiber photometrically rather than at a single-neuron level, it is possible that we were unable to resolve the diversity of VTA VGluT2 neuron responses to reward using GCaMP.

A subset of VTA VGluT2 neurons increases firing in response to both rewarding and aversive stimuli, suggesting this subpopulation functions as salience detectors (Root et al., 2018). A separate subset of VTA VGluT2 neurons decreases firing in response to reward and increases firing to aversive stimuli, suggesting they may participate in aversion (Root et al., 2018). Our iGluSnFR recordings mirror these results, identifying one population of glutamate inputs that increases in response to both rewarding and aversive stimuli, and another population of glutamate inputs that decreases in response to reward but increases in response to aversive stimuli. However, the proportion of neurons that increase firing at reward in our prior electrophysiological examination was less than the proportion of reward-increasing iGluSnFR mice in the present study. It is important to note that our prior electrophysiological characterization of VTA VGluT2 neurons used optogenetically phototagged VGluT2 neurons. Neurons with optogenetic responses that did not meet firing change latency or fidelity criterions were omitted from consideration. Some of these VTA-localized optogenetic responsive neurons that did not meet the phototagging criterion increased firing in response to motivationally-relevant events such as reward predictive cues and reward presentation. Therefore, it is likely that our prior electrophysiological examination of VTA VGluT2 neuron firing represents a subset of VTA VGluT2 neurons. Additionally, because the present study leveraged population-level fiber photometry, we may have been less sensitive to detecting heterogenous subgroup neuronal activity. Single-cell optical recordings may better capture heterogenous signaling patterns from VTA VGluT2 neuron subtypes during motivated behavior. Lastly, the relationship between VTA glutamate neuron firing and calcium activity as reported by GCaMP is unclear. GCaMP6m has slower time scale dynamics compared with action potentials. Further, while extracellular sources of calcium contribute to GCaMP signaling and are likely to depolarize neurons, calcium-induced calcium-release from intracellular sources that also contribute to GCaMP signaling can activate $\mathrm{K}^{+}$currents to reduce neuronal firing (Kawano et al., 2020).

Despite their diverse signaling of reward, all iGluSnFR recordings on VTA VGluT2 neurons increased activity following aversive cues and events. iGABASnFR activity mostly decreased following aversive cues and events. Two mice within the iGABASnFR cohort showed an increase in activity directly following foot shock which was then followed by a marked decrease. This heterogeneity may highlight that distinct VTA VGluT2 neurons may receive different neurochemical inputs. Additionally, although iGABASnFR signals to VTA VGluT2 neurons decreased for most examined events it is important to note that iGABASnFR activity to these neurons can increase. We commonly observed an increase in iGABASnFR signal from baseline during the late phase of the interval between ShkCS+ and shock outcome. This increase in iGABASnFR may aid in discriminating aversion-predicting cues from the receipt of an aversive outcome. At the aversive shock outcome, we interpret the enhanced iGluSnFR activity, together with the decreased iGABASnFR activity as a mechanism that increases the activity of VTA VGluT2 neurons in response to aversive stimuli. This result may partially explain why most VTA VGluT2 neurons increase firing rates in response to aversive facial airpuffs (Root et al., 2018).

Given that VTA dopamine neurons signal negative prediction error following unexpected reward omission (Schultz, 1998), we 
aimed to identify whether glutamate or GABA inputs to VTA VGluT2 neurons are sensitive to negative prediction errors. The iGluSnFR and iGABASnFR patterns of activity were not different between reward trials and reward error trials. This suggests that GABA and glutamate input to VGluT2 neurons are influenced by the anticipation and consumption of reward but are insensitive to reward omission. Movement-related analysis also suggests that each measured neurochemical input to VTA VGluT2 neurons is sensitive to behaviors occurring immediately before reward-port entry following conditioning. However further research is needed to dissect the specific behaviors involved in these signaling dynamics.

When recording VTA VGluT2 intracellular calcium signaling via GCaMP, we found that the activity of VTA VGluT2 neurons was reduced following reward omission compared with reward receipt. The calcium signal following reward omission slowly decayed instead of sharply rising as seen following expected reward delivery. This suggests that VTA VGluT2 neurons may discriminate between expected reward delivery and reward omission, but there is no negative inflection that might indicate a negative prediction error as observed with reward omission signaling in VTA dopamine neurons. Alternatively, because the reward omission condition results in reduced licking compared with reward receipt conditions, it is possible that the difference in signaling between conditions is related to consummatory behaviors. To test this possibility, we recorded GCaMP activity from VTA VGluT2 neurons during a task where mice were rewarded by licking a spout during the $\mathrm{CS}+$. Comparing lick trials during the CS + or CS error cues, we observed no difference in GCaMP activity at the population level. These data suggest that consummatory behaviors can influence VTA VGluT2 neuron signaling in the absence of reward. However, because GCaMP activity started ramping before the first lick, it is possible that the approach behavior immediately before licking may have influenced GCaMP signaling in both cases. As a subset of VTA GABA neurons are sensitive to body part movements (Hughes et al., 2019), and a subset of VTA glutamate neurons are also GABAergic (Root et al., 2014b), further research will be necessary to disentangle various movement-related activities from reward-related signaling.

Glutamate and GABA inputs to VTA VGluT2 neurons were modulated by learned predictors (conditioned stimuli) of rewarding and aversive outcomes. Glutamate input to VTA VGluT2 neurons was significantly increased at the presentation of rewardpredicting (RewCS+) and aversion-predicting (ShkCS+) cues. Previous work established that VTA VGluT2 neurons increase firing following aversive air puff. The present data also show that these neurons signal the anticipation of aversion. Our iGluSnFR data in coordination with GCaMP recordings, demonstrate that VTA VGluT2 neurons are indeed activated by cues predicting aversive outcomes involving at least direct glutamatergic excitation. Altogether, it appears that select glutamate inputs to VTA VGluT2 neurons may more reliably signal reward-related events than others, but glutamate inputs are strongly relayed to VTA VGluT2 neurons following aversion-related cues and events. GABA inputs on the other hand, typically decrease activity following reward or aversion-related predictors and subsequent outcomes. During reward conditioning, cues that predicted the absence of sucrose delivery did not alter neurotransmitter or calcium signaling to VTA VGluT2 neurons. While no sensor detected a significant change in activity following the RewCS-, all glutamate inputs significantly increased and GABA inputs significantly decreased following the ShkCS- that predicted the absence of footshock. It is possible that the ShkCS- signaling reflected a generalized freezing behavior to this stimulus, though significantly less than the ShkCS+. Alternatively, it is also possible the ShkCSserved a "safety" signal that might be interpreted as reward-predicting (Christianson et al., 2011, 2012; Fernando et al., 2014).

We examined whether the electrophysiological diversity of VTA VGluT2 neurons is related to increasing or decreasing glutamatergic excitation or GABAergic disinhibition. To identify how glutamate and GABA affect VTA VGluT2 neuron firing, we recorded from VTA VGluT2 neurons ex vivo in the presence of glutamate and/or GABA receptor antagonists or agonists. AMPA/NMDA receptor antagonists significantly reduced VTA VGluT2 neuron firing compared with baseline, whereas GABAA receptor antagonists did not significantly change firing compared with baseline. The decreased firing following AMPA/ NMDA receptor antagonism indicates that a tonic level of glutamate input is necessary for maintaining baseline firing rates in VTA VGluT2 neurons. It is unlikely that the concentration of bicuculline was too low to detect changes in firing because the concentration used is sufficient to disinhibit VTA dopamine neurons by nearly $50 \%$ of basal rates (Xiao et al., 2007). This result indicates that a reduction in GABA-A receptor activity is insufficient to increase VTA VGluT2 neuron firing through a disinhibitory mechanism. Given that VTA VGluT2 neurons are known to rest close to the GABAergic reversal potential (Hnasko et al., 2012), it is unsurprising that blocking GABA-A receptors had little effect on firing, as one would not expect a significant hyperpolarization of the membrane potential in this situation. Rather, GABA may be primarily working through shunting inhibition (Eccles, 1964), in which the activation of GABA-A receptors leads to a local decrease in the input resistance, thereby reducing the amplitude of nearby EPSPs. Therefore, the loss of GABAergic release that occurs during an aversive event would result in more effective excitatory synaptic transmission.

Similar results were found from experiments using AMPA/ NMDA and GABA-A receptor agonists. VTA VGluT2 neurons robustly increased spontaneous firing following AMPA/NMDA application. A lower concentration of the GABA-A receptor agonist isoguvacine $(10 \mu \mathrm{M})$ that is sufficient to reduce VTA dopamine neuron firing by nearly $50 \%$ of basal rates (Lobb et al., 2010), did not significantly reduce the firing rate of VGluT2 neurons. However, a higher concentration of isoguvacine $(50 \mu \mathrm{M})$ did abolish firing of VGluT2. These data suggest that strong activation of GABA-A receptors decreases the firing rate of VGluT2 neurons. Taken together, our electrophysiological results indicate that changes in firing by VTA VGluT2 neurons are directly driven by increasing or decreasing fluctuations in glutamate input. Specifically, removal of glutamate receptor activity results in disexcitation of VTA VGluT2 neurons while activation of glutamate receptor activity increases VTA VGluT2 neuron firing. While GABA-A agonism was sufficient to decrease the firing of VTA VGluT2 neurons, GABA-A antagonism was not sufficient to increase the firing rate of VGluT2 neurons. It is also plausible that GABA-B receptors or other inhibitory neurotransmitters such as glycine play a larger role in inhibiting VTA VGluT2 neurons. It is important to note that ex vivo experiments were conducted in slices in which long-range connections have been severed, it is therefore possible that additional glutamatergic and GABAergic inputs may regulate firing of VGluT2 neurons in ways not captured by these experiments. It should also be noted that our ex vivo recordings of agonist-induced firing occurred with intact synaptic transmission. Therefore, it is possible that the observed changes in firing of VTA VGluT2 neurons were 
not only influenced by glutamate and GABA receptors expressed by VGluT2 neurons but also by nonVGluT2 neurons also expressing glutamate and GABA receptors.

VTA VGluT2 neurons process and signal multiple aspects of motivated behavior, including reward and aversion (Root et al., 2014a, 2018; Wang et al., 2015; Yoo et al., 2016). Here, we identified that glutamate and GABA inputs to VTA VGluT2 neurons are modulated by reward and aversion predicting cues and outcomes. Glutamate inputs in particular, show the same diverse responses of VTA VGluT2 neurons following reward as electrophysiological firing patterns (Root et al., 2018). Together with the identification that glutamate receptor activity strongly regulates VTA VGluT2 neuron firing, we hypothesize that distinct glutamate inputs drive VTA VGluT2 neuron participation in different motivated behaviors. Lastly, our results indicate that neurotransmitter sensors serve as a powerful tool to identify neurochemical influences that control motivated behavior and expand on the electrophysiological firing patterns that underlie them.

\section{References}

Barbano MF, Wang HL, Zhang S, Miranda-Barrientos J, Estrin DJ, FigueroaGonzález A, Liu B, Barker DJ, Morales M (2020) VTA glutamatergic neurons mediate innate defensive behaviors. Neuron 107:368-382.e8.

Barker DJ, Miranda-Barrientos J, Zhang S, Root DH, Wang HL, Liu B, Calipari ES, Morales M (2017) Lateral preoptic control of the lateral habenula through convergent glutamate and GABA transmission. Cell Rep 21:1757-1769.

Barrot M (2014) The ventral tegmentum and dopamine: a new wave of diversity. Neuroscience 282:243-247.

Bimpisidis Z, König N, Stagkourakis S, Zell V, Vlcek B, Dumas S, Giros B, Broberger C, Hnasko TS, Wallén-Mackenzie A (2019) The NeuroD6 subtype of VTA neurons contributes to psychostimulant sensitization and behavioral reinforcement. eNeuro 6:ENEURO.0066-19.2019.

Bocklisch C, Pascoli V, Wong JCY, House DRC, Yvon C, de Roo M, Tan KR, Lüscher C (2013) Cocaine disinhibits dopamine neurons by potentiation of GABA transmission in the ventral tegmental area. Science 341:15211525.

Cai LX, Pizano K, Gundersen GW, Hayes CL, Fleming WT, Holt S, Cox JM, Witten IB (2020) Distinct signals in medial and lateral VTA dopamine neurons modulate fear extinction at different times. Elife 9:e54936.

Christianson JP, Jennings JH, Ragole T, Flyer JG, Benison AM, Barth DS, Watkins LR, Maier SF (2011) Safety signals mitigate the consequences of uncontrollable stress via a circuit involving the sensory insular cortex and bed nucleus of the stria terminalis. Biol Psychiatry 70:458-464.

Christianson JP, Fernando AB, Kazama AM, Jovanovic T, Ostroff LE, Sangha S (2012) Inhibition of fear by learned safety signals: a mini-symposium review. J Neurosci 32:14118-14124.

Cohen JY, Haesler S, Vong L, Lowell BB, Uchida N (2012) Neuron-type-specific signals for reward and punishment in the ventral tegmental area. Nature 482:85-88.

Corre J, van Zessen R, Loureiro M, Patriarchi T, Tian L, Pascoli V, Lüscher C (2018) Dopamine neurons projecting to medial shell of the nucleus accumbens drive heroin reinforcement. Elife 7:e39945.

Eccles J (1964) The physiology of nerve cells. Baltimore: Springer.

Faget L, Osakada F, Duan J, Ressler R, Johnson AB, Proudfoot JA, Yoo JH, Callaway EM, Hnasko TS (2016) Afferent inputs to neurotransmitterdefined cell types in the ventral tegmental area. Cell Rep 15:2796-2808.

Fernando AB, Urcelay GP, Mar AC, Dickinson A, Robbins TW (2014) Safety signals as instrumental reinforcers during free-operant avoidance. Learn Mem 21:488-497.

Hnasko TS, Hjelmstad GO, Fields HL, Edwards RH (2012) Ventral tegmental area glutamate neurons: electrophysiological properties and projections. J Neurosci 32:15076-15085.

Holly EN, Miczek KA (2016) Ventral tegmental area dopamine revisited: effects of acute and repeated stress. Psychopharmacology (Berl) 233:163186.
Hughes RN, Watson GDR, Petter EA, Kim N, Bakhurin KI, Yin HH (2019) Precise coordination of three-dimensional rotational kinematics by ventral tegmental area GABAergic neurons. Curr Biol 29:3244-3255.e4.

Jennings JH, Sparta DR, Stamatakis AM, Ung RL, Pleil KE, Kash TL, Stuber GD (2013) Distinct extended amygdala circuits for divergent motivational states. Nature 496:224-228.

Kawano H, Mitchell SB, Koh JY, Goodman KM, Harata NC (2020) Calciuminduced calcium release in noradrenergic neurons of the locus coeruleus. Brain Res 1729:146627.

Levi LA, Inbar K, Nachshon N, Bernat N, Gatterer A, Inbar D, Kupchik YM (2020) Projection-specific potentiation of ventral pallidal glutamatergic outputs after abstinence from cocaine. J Neurosci 40:1276-1285.

Liu Y, Jean-Richard-Dit-Bressel P, Yau JO, Willing A, Prasad AA, Power JM, Killcross S, Clifford CWG, McNally GP (2020) The mesolimbic dopamine activity signatures of relapse to alcohol-seeking. J Neurosci 40:6409-6427.

Lobb CJ, Wilson CJ, Paladini CA (2010) A dynamic role for GABA receptors on the firing pattern of midbrain dopaminergic neurons. J Neurophysiol 104:403-413.

Marvin JS, Schreiter ER, Echevarría IM, Looger LL (2011) A genetically encoded, high-signal-to-noise maltose sensor. Proteins 79:3025-3036.

Marvin JS, Scholl B, Wilson DE, Podgorski K, Kazemipour A, Müller JA, Schoch S, Quiroz FJU, Rebola N, Bao H, Little JP, Tkachuk AN, Cai E, Hantman AW, Wang SSH, DePiero VJ, Borghuis BG, Chapman ER, Dietrich D, DiGregorio DA, et al. (2018) Stability, affinity, and chromatic variants of the glutamate sensor iGluSnFR. Nat Methods 15:936-939.

Marvin JS, Shimoda Y, Magloire V, Leite M, Kawashima T, Jensen TP, Kolb I, Knott EL, Novak O, Podgorski K, Leidenheimer NJ, Rusakov DA, Ahrens MB, Kullmann DM, Looger LL (2019) A genetically encoded fluorescent sensor for in vivo imaging of GABA. Nat Methods 16:763-770.

Mingote S, Chuhma N, Kalmbach A, Thomsen GM, Wang Y, Mihali A, Sferrazza C, Zucker-Scharff I, Siena AC, Welch MG, Lizardi-Ortiz J, Sulzer D, Moore H, Gaisler-Salomon I, Rayport S (2017) Dopamine neuron dependent behaviors mediated by glutamate cotransmission. Elife 6: e27566.

Morales M, Root DH (2014) Glutamate neurons within the midbrain dopamine regions. Neuroscience 282:60-68.

Morales M, Margolis EB (2017) Ventral tegmental area: cellular heterogeneity, connectivity and behaviour. Nat Rev Neurosci 18:73-85.

Nunemaker CS, DeFazio RA, Moenter SM (2003) A targeted extracellular approach for recording long-term firing patterns of excitable cells: a practical guide. Biol Proced Online 5:53-62.

Pascoli V, Terrier J, Hiver A, Lüscher C (2015) Sufficiency of mesolimbic dopamine neuron stimulation for the progression to addiction. Neuron 88:1054-1066.

Polter AM, Barcomb K, Tsuda AC, Kauer JA (2018) Synaptic function and plasticity in identified inhibitory inputs onto VTA dopamine neurons. Eur J Neurosci 47:1208-1218.

Root DH, Fabbricatore AT, Ma S, Barker DJ, West MO (2010) Rapid phasic activity of ventral pallidal neurons during cocaine self-administration. Synapse 64:704-713.

Root DH, Mejias-Aponte CA, Qi J, Morales M (2014a) Role of glutamatergic projections from ventral tegmental area to lateral habenula in aversive conditioning. J Neurosci 34:13906-13910.

Root DH, Mejias-Aponte CA, Zhang S, Wang HL, Hoffman AF, Lupica CR, Morales M (2014b) Single rodent mesohabenular axons release glutamate and GABA. Nat Neurosci 17:1543-1551.

Root DH, Wang HL, Liu B, Barker DJ, Mód L, Szocsics P, Silva AC, Maglóczky Z, Morales M (2016) Glutamate neurons are intermixed with midbrain dopamine neurons in nonhuman primates and humans. Sci Rep 6:30615.

Root DH, Estrin DJ, Morales M (2018) Aversion or salience signaling by ventral tegmental area glutamate neurons. iScience 2:51-62.

Root DH, Barker DJ, Estrin DJ, Miranda-Barrientos JA, Liu B, Zhang S, Wang HL, Vautier F, Ramakrishnan C, Kim YS, Fenno L, Deisseroth K, Morales M (2020) Distinct signaling by ventral tegmental area glutamate, GABA, and combinatorial glutamate-GABA neurons in motivated behavior. Cell Rep 32:108094.

Scaplen KM, Kaun KR (2016) Reward from bugs to bipeds: a comparative approach to understanding how reward circuits function. J Neurogenet 30:133-148. 
Schultz W (1998) Predictive reward signal of dopamine neurons. J Neurophysiol 80:1-27.

Stuber GD, Hnasko TS, Britt JP, Edwards RH, Bonci A (2010) Dopaminergic terminals in the nucleus accumbens but not the dorsal striatum corelease glutamate. J Neurosci 30:8229-8233.

Tan KR, Yvon C, Turiault M, Mirzabekov JJ, Doehner J, Labouèbe G, Deisseroth K, Tye KM, Lüscher C (2012) GABA neurons of the VTA drive conditioned place aversion. Neuron 73:1173-1183.

Taylor SR, Badurek S, Dileone RJ, Nashmi R, Minichiello L, Picciotto MR (2014) GABAergic and glutamatergic efferents of the mouse ventral tegmental area. J Comp Neurol 522:3308-3334.

Ting JT, Daigle TL, Chen Q, Feng G (2014) Acute brain slice methods for adult and aging animals: application of targeted patch clamp analysis and optogenetics. Methods Mol Biol 1183:221-242.

van Zessen R, Phillips JL, Budygin EA, Stuber GD (2012) Activation of VTA GABA neurons disrupts reward consumption. Neuron 73:1184-1194.
Wang HL, Qi J, Zhang S, Wang H, Morales M (2015) Rewarding effects of optical stimulation of ventral tegmental area glutamatergic neurons. J Neurosci 35:15948-15954.

Wise RA (2004) Dopamine, learning and motivation. Nat Rev Neurosci 5:483-494.

Wise RA, Bozarth MA (1981) Brain substrates for reinforcement and drug self-administration. Prog Neuropsychopharmacol 5:467-474.

Xiao C, Zhang J, Krnjević K, Ye JH (2007) Effects of ethanol on midbrain neurons: role of opioid receptors. Alcohol Clin Exp Res 31:1106-1113.

Yamaguchi T, Sheen W, Morales M (2007) Glutamatergic neurons are present in the rat ventral tegmental area. Eur J Neurosci 25:106-118.

Yoo JH, Zell V, Gutierrez-Reed N, Wu J, Ressler R, Shenasa MA, Johnson AB, Fife KH, Faget L, Hnasko TS (2016) Ventral tegmental area glutamate neurons co-release GABA and promote positive reinforcement. Nat Commun 7:13697. 